\title{
SPONTANEOUS ATLANTO-AXIAL DISLOCATION IN ANKYLOSING SPONDYLITIS AND RHEUMATOID ARTHRITIS
}

\author{
BY \\ J. SHARP AND D. W. PURSER \\ From the University Departments of Rheumatism Research and Orthopaedic Surgery, Manchester
}

Spontaneous atlanto-axial dislocation is a recognized if rare complication of infections of the pharynx and neck (Bell, 1830; Grisel, 1930; Watson-Jones, 1932) and of childhood rheumatic fever (Coutts, 1934). Werne (1957) reviewed the literature relating to the 176 cases reported up to that time in which the dislocation occurred in the course of various illnesses either without or with only trivial injury, and described seven further examples he had observed personally, five of them in children suffering from chronic polyarthritis. In this extensive literature, only isolated or small numbers of cases have been reported in which the lesion occurred as a complication of ankylosing spondylitis or rheumatoid arthritis.

Stammers and Frazer (1933) described a man aged 30 with advanced ankylosing spondylitis (Stammers, 1956) who developed pyramidal signs and sensory changes in the right lower limb and weakness of grip in the left hand as a result of forward dislocation of the atlas on the axis. The neurological abnormalities regressed after the head was extended and a plaster cast was applied. Rand (1944) reported a man probably suffering from ankylosing spondylitis in whom a Brown-Séquard syndrome was associated with atlanto-axial dislocation and Coste, Auquier, and Civatte (1952) described the case of a 37-year-old female said to be suffering from both ankylosing spondylitis and a primary chronic polyarthritis of 5 years' duration in whom atlantoaxial dislocation occurred without neurological complications. Kornblum, Clayton, and Nash (1952) reported two male patients with ankylosing spondylitis with severe forward displacement of the atlas; neurological complications were present in one case only and these disappeared after reduc- tion of the dislocation by skull traction. Brocher (1955) gave brief clinical descriptions of two men with ankylosing spondylitis and atlanto-axial subluxation; in one this was spontaneous but in the other it is possible that displacement may have followed tonsillectomy. Morrison (1955) referred to a 31-year-old soldier suffering from severe and rapidly-progressing ankylosing spondylitis who developed a tetraparesis which was at first attributed to protrusion of a cervical disk but was subsequently found to be due to atlanto-axial dislocation (Morrison, Baird, and Logue, 1957). Wilkinson and Bywaters (1958) mention a patient with ankylosing spondylitis who complained of neck pain in whom radiographs disclosed atlanto-axial subluxation, and Pratt (1959) described two patients with severe ankylosing spondylitis who developed spontaneous atlanto-axial dislocations, one of whom was treated by occipito-cervical fusion.

Davis and Markley (1951) reported the clinical and autopsy findings in a 58-year-old female with severe nodular rheumatoid arthritis in whom the disease had resulted in severe destructive changes in the atlas, axis, and occiput with resulting dislocation of the atlas and compression of the medulla oblongata just below the pons by the odontoid process. The ganglion cells of the medulla showed pyknosis, eccentric nuclei, and vacuolization of the cytoplasm, but the brain and spinal cord were otherwise normal and there was no evidence of demyelination. Vignon and Patet (1955) described a 46-year-old woman who had developed an atlantoaxial displacement in association with rheumatoid arthritis of 8 years' duration. Storey (1958) reported the case of a 53-year-old woman with rheumatoid arthritis with a severe cord lesion who 
died suddenly although wearing a protective collar; at autopsy the spinal cord was found to be compressed by the odontoid process which was displaced upwards through the foramen magnum from subluxation of the atlas on the axis. Pratt (1959) described the case of a 56-year-old woman with severe rheumatoid arthritis who developed tetraplegia as a result of atlanto-axial dislocation. Neurological improvement followed traction and the application of a cervical support, but she subsequently deteriorated, lost weight, developed melancholia, faecal and urinary incontinence, and decubitus ulceration, and died 7 months later.

In addition to these reports of the occurrence of atlanto-axial displacement in patients in whom rheumatoid arthritis began in adult life, this complication has also been observed in children with the disease (Potter, Barkin, and Stillman, 1954; Werne, 1957; Le Baudour and Freyberg, 1958) and also in a woman aged 31 in whom the arthritis had begun at age 10 and who had suffered from occipitocervical pain from the age of 27 years (de Sèze, Djian, and Caroit, 1957).

In 1957 we reported ten patients with ankylosing spondylitis and two with rheumatoid arthritis who had developed spontaneous atlanto-axial displacements (Sharp and Purser, 1957). The purpose of the present communication is to report a further twelve patients with spondylitis and 24 with rheumatoid arthritis who have developed this complication, to point out that this is probably not a rare complication of advanced ankylosing spondylitis and is common in rheumatoid arthritis, and to describe the clinical features of the condition.

\section{Radiological Criteria for Diagnosis}

Coutts (1934) stated that an increase in the interval between the odontoid process and the anterior arch of the atlas was, in the absence of fracture of the odontoid process, the only pathognomonic radiological sign of atlanto-axial subluxation. From clinical observations, radiographic studies of himself, and published anatomical data, he concluded that normally the interval between the front of the dens and the back of the anterior arch of the atlas does not exceed $2 \mathrm{~mm}$. Jackson (1950) examined lateral films of fifty adults taken in flexion and extension and found that the distance between the postero-inferior margin of the anterior arch of the atlas and the anterior surface of the dens did not alter and was never more than $2.5 \mathrm{~mm}$. In eleven out of 25 children examined similarly, this interval increased in flexion to a maximum of $3 \mathrm{~mm}$., the greatest increase observed in this series being from 2 to $3 \mathrm{~mm}$. In another child age $6 \frac{1}{2}$ years who was referred to hospital 3 days afte a head injury, the interval increased from 2.5 tब $4.5 \mathrm{~mm}$. on flexion. The child, who was symptom less, had no history of cervical infection and had a. full range of cervical movement so that these measurements were presumably normal in his caseIn studies of post-mortem preparations of the cervicaf spine, Werne (1957) found no forward slippinge of the atlas on the axis on flexion until the transversed ligament retaining the odontoid process to the anterior arch of the atlas was divided; the disloca $\mathrm{E}$ tion then occurring tended to be greater in subjects below the age of 25 . In flexion and extension films of 104 subjects aged from 10 to 62 years, eithef5 volunteers or patients suffering from trauma or loca disease not involving the cranio-vertebral joints he observed no forward movement of the atlas? although the cephalic end of the gap between the odontoid and anterior arch of the atlas usually became wider on flexion.

\section{Prevalence Studies}

All previous studies of the radiological criteria of normality had been made on hospital patients or normal volunteers, and it was felt that a mogre accurate definition of normality could be derisco from studying radiographs of samples of the genepiri population in which the prevalence of rheumatic disease had already been studied in detail (Kellgrenf and Lawrence, 1956, 1958; Lawrence, 1960).

General Population Sample.-The radiographs of the cervical spine of the population samples madeavailable to us were single lateral films. It waș appreciated that the absence of forward displace ment of the atlas on a single lateral film taken in mid-position by no means excludes a mobile dis placement which may be only apparent on a film taken in flexion (Fig. 1, opposite). The estimateso of prevalence of atlanto-axial displacements in the general population derived from this study are therefore minimum values.

The number of films from the members of the general population examined was 1,478. Somen 1,200 of these were from a random sample of the population over the age of 14 years in the Lancashires town of Leigh, and the remainder were from random sample of females aged 55 to 64 years ing the Vale of Glamorgan, from relatives of subjectso with rheumatoid arthritis or multiple osteo-arthrosis $\widetilde{\mathbb{D}}$ and a small additional sample of people over the? age of 75 in Leigh. In addition to radiographs ofo the cervical spine, $x$ rays of the hands, feet, and in 


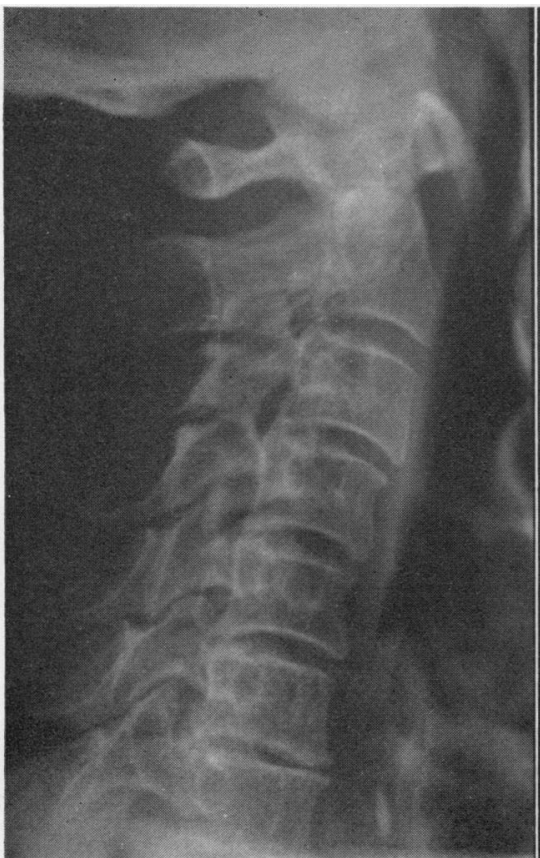

(a)

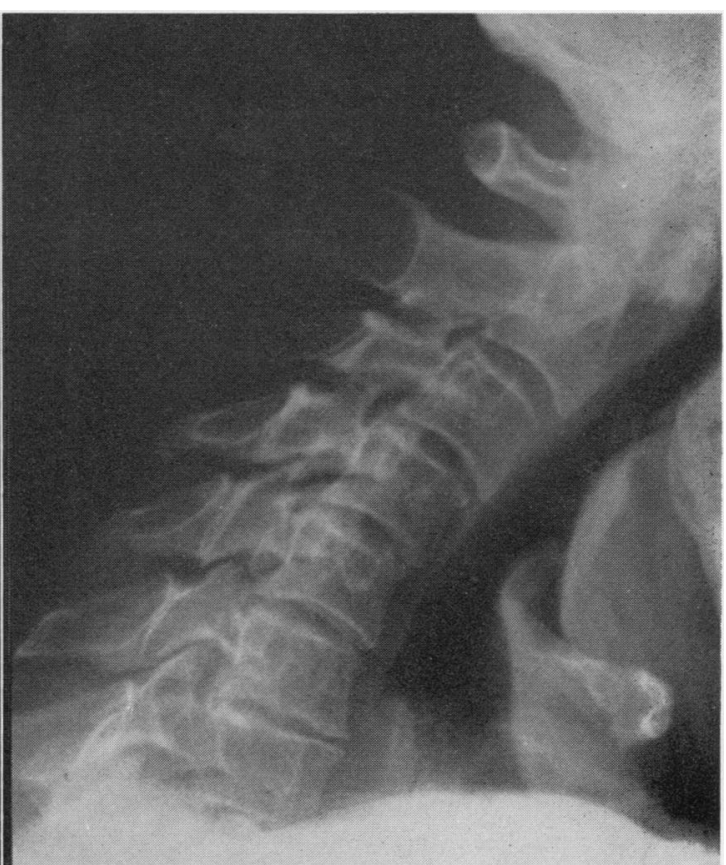

(b)

Fig. 1.-(a) Conventional lateral view of a patient with rheumatoid arthritis; (b) Film taken in flexion of the same patient. The atlanto-axial subluxation is visible only on the film taken in flexion.

most cases other sites, had been taken in almost all of these individuals as well as a medical history, a clinical examination of the limbs and spine, and a sheep cell agglutination test (performed by the method of Ball, 1950).

The distribution of the distances between the middle of the anterior arch of the atlas and the front of the odontoid process at various ages of the whole group is shown in Table I. The numbers with evidence of rheumatoid arthritis are also shown. Only four subjects with spondylitis, all males, were encountered in the population sample, and the interval measured $3 \mathrm{~mm}$. or less in each case. It will be seen that six of the seven individuals over

TABLE I

MEASUREMENTS OF INTERVAL BETWEEN ODONTOID PROCESS AND ANTERIOR ARCH OF ATLAS ON RADIOGRAPHS OF TOTAL SAMPLE OF GENERAL POPULATION

\begin{tabular}{|c|c|c|c|c|c|c|c|c|c|c|c|c|}
\hline \multirow{3}{*}{$\begin{array}{c}\text { Age } \\
\text { (yrs) }\end{array}$} & \multirow{3}{*}{$\begin{array}{l}\text { Total } \\
\text { Films }\end{array}$} & \multirow{3}{*}{$\begin{array}{c}\text { Total } \\
\text { with } \\
\text { Rheumatoid } \\
\text { Arthritis* }\end{array}$} & \multicolumn{10}{|c|}{ Distance between Front of Odontoid and Back of Arch of Atlas (mm.) } \\
\hline & & & \multicolumn{2}{|c|}{3 or Less } & \multicolumn{2}{|c|}{$3 \cdot 1$ to $3 \cdot 5$} & \multicolumn{2}{|c|}{$3 \cdot 6$ to $4 \cdot 0$} & \multicolumn{2}{|c|}{$4 \cdot 1$ to $4 \cdot 5$} & \multicolumn{2}{|c|}{$>4 \cdot 5$} \\
\hline & & & Total & R.A. & Total & R.A. & Total & R.A. & Total & R.A. & Total & R.A. \\
\hline $\begin{array}{l}15-24 \\
25-34 \\
35-44 \\
45-54 \\
55-64 \\
65-74 \\
75+\end{array}$ & $\begin{array}{r}72 \\
221 \\
227 \\
296 \\
454 \\
144 \\
64\end{array}$ & $\begin{array}{r}1 \\
14 \\
17 \\
30 \\
77 \\
34 \\
13\end{array}$ & $\begin{array}{r}69 \\
218 \\
226 \\
295 \\
451 \\
141 \\
64\end{array}$ & $\begin{array}{r}1 \\
14 \\
17 \\
29 \\
74 \\
32 \\
13\end{array}$ & $\begin{array}{l}2 \\
3 \\
1 \\
1 \\
1\end{array}$ & $\begin{array}{l}0 \\
0 \\
0 \\
1 \\
1\end{array}$ & 1 & 0 & 1 & 0 & $\begin{array}{l}1 \\
1 \\
1\end{array}$ & $\begin{array}{l}1 \\
1 \\
1\end{array}$ \\
\hline Total & 1,478 & 186 & 1,464 & 180 & 8 & 2 & 2 & 1 & 1 & 0 . & 3 & 3 \\
\hline
\end{tabular}

* The following criteria were taken as evidence of rheumatoid arthritis:

(1) Definite clinical evidence, and/or

(2) Definite radiological signs of the disease in the hands or feet, and/or

(3) Agglutination at a titre greater than 1/16 in the sheep cell agglutination test (Ball, 1950). 
the age of 45 in whom the interval was more than $3 \mathrm{~mm}$. had evidence of rheumatoid arthritis; the exception was a man aged 72 who had suffered from osteomyelitis of the mandible between the ages of 8 and 16 and who might have developed a "hyperaemic" displacement during this period (Watson Jones, 1932). Films in flexion and extension were obtained in five of these seven individuals; in one the interval on the film taken in flexion was the same as that on the original film, in two it was slightly greater, and in two (including the subject whose original film is illustrated in Fig. 2), the distance could not be measured accurately for technical reasons but was greater than $3 \mathrm{~mm}$. It therefore appears reasonable to regard a separation of the odontoid process from the anterior arch of the atlas of more than $3 \mathrm{~mm}$. as abnormal after the age of 44 , although a gap of $4 \mathrm{~mm}$. may be normal in younger individuals and clinical evidence would strongly suggest that occasionally a gap of even $3 \mathrm{~mm}$. after the age of 44 may be abnormal (Cases 14 and 17; Tables V and VII).

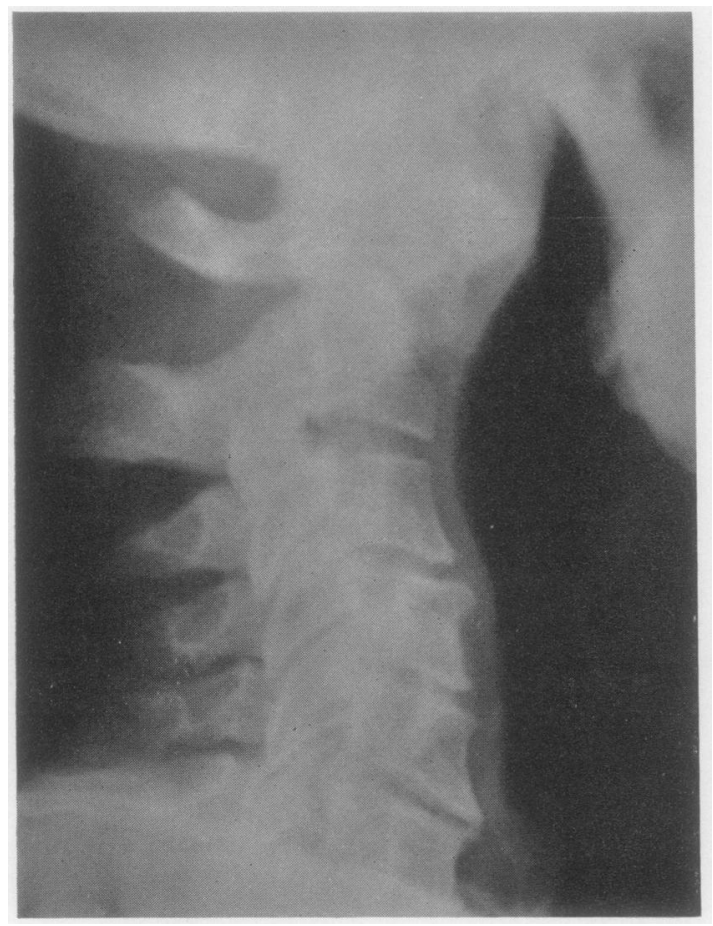

Fig. 2.-Radiograph of a man aged 59 in the random sample of the general population, showing well-marked forward displacement of the atlas. He had clinical evidence of severe rheumatoid arthritis and the sheep call agglutination titre was $1 / 128$.

The random sample of the general population contained an excess of individuals in the 55 to 64-year age group and the numbers with atlanto axial displacements in the various decades afte correction for this are shown in Table II. The incidence in the population aged 15 years and over was thus 2.6 per thousand $(3 / 1,176)$ and in those. over 55 years 8.5 per thousand $(3 / 354)$. EacF of the three individuals with an atlanto-axial dis: placement had clinical evidence of severe rheumatois arthritis and a positive sheep cell agglutination test

TABLE II

PREVALENCE OF ATLANTO-AXIAL DISPLACEMENTS ON RADIOGRAPHS OF A RANDOM SAMPLE OF THE GENERAL POPULATION

\begin{tabular}{|c|c|c|}
\hline $\begin{array}{l}\text { Age } \\
\text { (yrs) }\end{array}$ & $\begin{array}{l}\text { Number of } \\
\text { Films }\end{array}$ & $\begin{array}{l}\text { Number of Atlanto-Axia } \\
\text { Displacements Found }\end{array}$ \\
\hline $\begin{array}{l}15-24 \\
25-34 \\
35-44 \\
45-54 \\
55-64 \\
65-74 \\
75\end{array}$ & $\begin{array}{r}74 \\
221 \\
228 \\
299 \\
197 \\
111 \\
46\end{array}$ & $\begin{array}{l}0 \\
0 \\
0 \\
0 \\
2 \\
1 \\
0\end{array}$ \\
\hline Total & 1,176 & 3 \\
\hline
\end{tabular}

Table I shows that a total of 186 of the 1,478 members of the general population had clinigas radiological, or serological evidence of rheumatid arthritis. Six of these 186 had atlanto-axial fiso placements, a prevalence of $32 \cdot 3$ per thousa Five of these six had clinical evidence of rheumatoig arthritis, whereas 108 of the 186 had no clinicas evidence of rheumatoid arthritis, 44 of them having radiological changes with or without a positive sheep cell test and 64 having only a positive sheep cell test without clinical or radiological evidence of the disease. Thus, of the 78 members of the general population who had clinical evidence of rheumatoid arthritis, five had atlanto-axial diso placements, a prevalence of $64 \cdot 1$ per thousancB. Kellgren and Lawrence (1956) have pointed ouis that approximately one half of the inflammatory polyarthritis occurring in middle-aged females it the general population and at present usually diag? nosed as rheumatoid arthritis may be of a differen nature, so that the prevalence of $64 \cdot 1$ per thousan is more accurately that in clinical "chronic inflamo matory polyarthritis" as a whole rather than in clinical rheumatoid arthritis as such.

Hospital In-Patients with Rheumatoid Arthritis. Lateral films with the cervical spine flexed an extended were taken as part of the routine radios logical survey of almost all patients admitted te hospital under the care of the Rheumatism Services 
During 1958, 33 males and 46 females suffering from inflammatory polyarthritis of rheumatoid type were admitted, and of these 31 males and 43 females had such films taken (Table III). Atlanto-axial displacements were demonstrated in four males and ten females, giving a prevalence in the combined sexes of 189 per thousand of those with radiographs and 178 per thousand of the group as a whole, assuming that those without radiographs did not have displacements. None of these patients had been admitted to hospital purely on account of the atlanto-axial displacement and in most of them this was only diagnosed after admission. All of those with displacements showed positive results in the sheep cell agglutination test.

This estimate of the prevalence of atlanto-axial displacement in severe rheumatoid arthritis is lower than that deduced from post-mortem studies. In autopsies of twenty patients with rheumatoid arthritis, the majority of whom had very severe disease, Ball (1960) found atlanto-axial displacements in eight subjects.

TABle III

PREVALENCE OF ATLANTO-AXIAL DISPLACEMENTS IN HOSPITAL IN-PATIENTS WITH RHEUMATOID ARTHRITIS, BY SEX

\begin{tabular}{|c|c|c|c|c|c|}
\hline Sex & .. & .. & Male & Female & Total \\
\hline No. of Patients & $\ldots$ & $\ldots$ & $33(31)$ & $46(38)$ & $79(69)$ \\
\hline No. of Films & $\ldots$ & . & $31(30)$ & $43(35)$ & $74(65)$ \\
\hline $\begin{array}{l}\text { No. of Atlanto- } \\
\text { ments Foun }\end{array}$ & $\begin{array}{l}\text { Axial I } \\
\text { d }\end{array}$ & $\begin{array}{c}\text { Displace- } \\
\ldots \quad . .\end{array}$ & $4(4)$ & $10(10)$ & $14(14)$ \\
\hline
\end{tabular}

Figures in brackets indicate the numbers giving agglutination at a titre greater than $1 / 16$ in the sheep cell agglutination test.

Ankylosing Spondylitis.--Seventeen of the present cases were encountered in the examination and follow-up of patients referred to a Spondylitis Clinic where some 1,000 patients had attended. A survey of all the patients was not possible and it is likely that the diagnosis was missed in some patients who were seen before we became aware of this lesion as a complication of ankylosing spondylitis. That this is so is suggested by the finding of one previously undiagnosed case of atlanto-axial subluxation in the films of 49 spondylitic patients of various ages who were recalled to have flexion and extension films taken of the cervical spine. This cannot be regarded as the true prevalence since the sample is small and a completely random selection could not be made, but it is clear that the prevalence in ankylosing spondylitis is substantially lower than in rheumatoid arthritis.
The estimates of the prevalence of atlanto-axial displacement are summarized in Table IV.

TABLE IV

PREVALENCE OF ATLANTO-AXIAL DISPLACEMENT

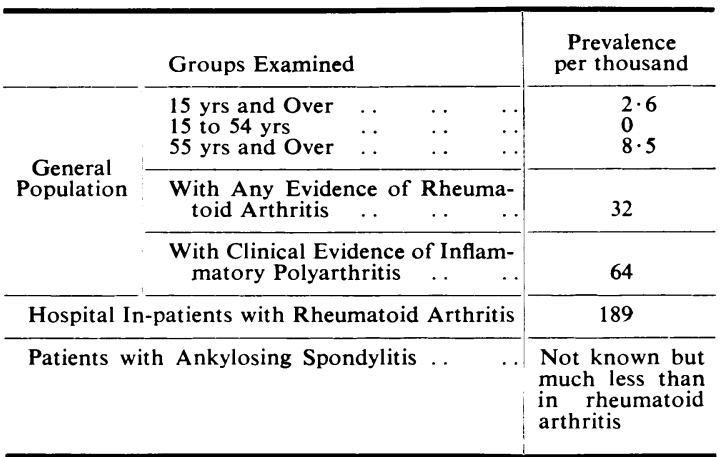

\section{Clinical Studies}

The general features of the patients with ankylosing spondylitis and rheumatoid arthritis with atlanto-axial displacement are shown in Tables $\mathrm{V}$ and VI (overleaf). Details of the cervical displacement and its treatment are set out in Tables VII and VIII (overleaf).

All the patients with spondylitis had bilateral radiographic changes in the sacro-iliac joints, and in Cases 1 to 18 the clinical and radiographic picture was typical of ankylosing spondylitis. In Cases 19 to 22 the diagnosis was less straightforward. Case 20, in which there was a severe polyarthritis affecting the spine and limbs and a complete tetraplegia from the dislocation, is to be described in detail elsewhere (Sharp and Purser, 1961). Accounts of Cases 19, 21 and 22 are given in the Appendix to the present communication.

The eighteen patients with typical ankylosing spondylitis ranged in age from 28 to 64 years when the atlanto-axial displacement was diagnosed; seven were in the fourth decade but the ages of the remainder were fairly evenly distributed. Symptoms of ankylosing spondylitis had been present for from 3 to 31 years, for less than 10 years in nine patients and for more than 20 years in only four. In the seventeen patients in whom this could be ascertained, the cervical region had been involved for from 6 months to 22 years, in nine for 5 years or less, and in only two for more than 10 years. In Case 1 the first symptoms in the cervical region were indicative of atlanto-axial subluxation, but in the remainder these had supervened after cervical involvement had been present for from 9 months 
GENERAL FEA

\begin{tabular}{|c|c|c|c|c|c|c|c|c|c|}
\hline \multirow[b]{2}{*}{ Spondylitis } & \multirow[b]{2}{*}{$\begin{array}{l}\text { Case } \\
\text { No. }\end{array}$} & \multirow[b]{2}{*}{ Sex } & \multirow[b]{2}{*}{$\begin{array}{c}\text { Age at } \\
\text { Diagnosis of } \\
\text { Dislocation } \\
\text { (yrs) }\end{array}$} & \multicolumn{3}{|c|}{ Duration to Diagnosis of Dislocation } & \multirow{2}{*}{$\begin{array}{c}\text { Disease } \\
\text { Activity at } \\
\text { Presumptive } \\
\text { Time of } \\
\text { Dislocation }\end{array}$} & \multicolumn{2}{|c|}{ Spinal Deformit $\frac{0}{x_{0}-3}$} \\
\hline & & & & $\begin{array}{c}\text { Symptoms of } \\
\text { Spondylitis } \\
\text { (yrs) }\end{array}$ & $\begin{array}{c}\text { Cervical } \\
\text { Symptoms } \\
\text { (yrs) }\end{array}$ & $\begin{array}{l}\text { Presumptive } \\
\text { Dislocation } \\
\text { to Diagnosis } \\
\text { (mths) }\end{array}$ & & $\begin{array}{l}\text { Lumbo- } \\
\text { Dorsal }\end{array}$ & 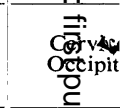 \\
\hline \multirow{18}{*}{ Typical } & 1 & $\mathbf{M}$ & 35 & 8 & $1: 2$ & 6 & \pm & 1 & $\overline{\bar{O}}_{0} 0$ \\
\hline & 2 & $\mathbf{M}$ & 31 & 3 & 3 & 26 & + & 2 & $\vec{D}^{1}$ \\
\hline & 3 & $\mathbf{M}$ & 38 & 7 & 6 & 60 & + & 3 & $\frac{2}{3}$ \\
\hline & 4 & $\mathbf{M}$ & 51 & 31 & $?$ & 6 & + & 1 & $\vec{o}^{1}$ \\
\hline & 5 & M & 38 & 19 & 8 & 30 & + & 1 & $\overrightarrow{\overrightarrow{\text { dex }} \text { xio }}$ \\
\hline & 6 & $\mathbf{M}$ & 28 & 5 & 5 & 3 & 0 & 1 & $R_{V^{\text {tatic }}}^{3}$ \\
\hline & 7 & $\mathbf{M}$ & 37 & 14 & 9 & 36 & + & 2 & $\mathrm{~N}^{2}$ \\
\hline & 8 & $\mathbf{M}$ & 46 & 16 & 16 & 14 & + & 2 & $\therefore 0$ \\
\hline & 9 & $\mathbf{M}$ & 54 & 9 & 4 & 2 & + & 2 & $\underset{\text { Thy }}{ \pm \sqrt{3}}$ \\
\hline & 10 & M & 61 & 23 & 7 & 8 & + & 2 & $\mathrm{~J}^{2}$ \\
\hline & 11 & $\mathbf{M}$ & 57 & 22 & 22 & 24 & + & 1 & $\bar{a}+$ \\
\hline & 12 & $\mathbf{M}$ & 64 & 7 & 7 & 36 & + & 2 & क्षे? \\
\hline & 13 & $\mathbf{M}$ & 29 & 6 & 4 & 18 & + & 1 & 1 \\
\hline & 14 & $\mathbf{M}$ & 64 & 20 & 5 & 9 & + & 3 & ᄋ $\mathscr{Q}_{1}$ \\
\hline & 15 & $\mathbf{M}$ & 32 & 5 & 5 & $?$ & + & 2 & $\nabla^{0}$ \\
\hline & 16 & $\mathbf{M}$ & 36 & 14 & 8 & 3 & 0 & 2 & केषे 0 \\
\hline & 17 & $\mathbf{F}$ & 55 & 25 & 5 & 12 & + & 1 & $\bar{F}{ }^{2} 2$ \\
\hline & 18 & $F$ & 29 & 4 & 4 & 5 & + & 2 & 응 0 \\
\hline \multirow{4}{*}{ Atypical } & 19 & $\mathbf{M}$ & 18 & $? 0$ & 0 & "Some" & 0 & 0 & $\begin{array}{l}\text { Farwa } \\
\text { inctinat } \\
\text { बु hea }\end{array}$ \\
\hline & 20 & $\mathbf{M}$ & 31 & 11 & 2 & 9 & + & 1 & 発xio \\
\hline & 21 & $\mathbf{M}$ & 40 & 20 & 20 & $1 \frac{1}{2}$ & 0 & 1 & 2 \\
\hline & 22 & $\mathbf{F}$ & 35 & 24 & 6 & $<12$ & + & 1 & $\frac{9}{2}$ \\
\hline \multicolumn{5}{|c|}{$\begin{array}{l}\text { to } 20 \text { years. The lumbar, dorsal, and lower cervical } \\
\text { regions were rigid or grossly restricted in motion } \\
\text { in fifteen patients, and ten had moderate or severe } \\
\text { lumbo-dorsal flexion deformities. Atlanto-occi- } \\
\text { pital movement, assessed clinically, was also greatly } \\
\text { decreased in fourteen of the eighteen patients, } \\
\text { seven of whom had moderate or severe occipito- } \\
\text { cervical deformity from the displacement. } \\
\text { The patients listed in Table VI (Cases } 23 \text { to 48) } \\
\text { all satisfied the criteria suggested in } 1958 \text { by the } \\
\text { American Rheumatism Association (Ropes, Bennett, } \\
\text { Cobb, Jacox, and Jessar, 1959) for a diagnosis of }\end{array}$} & \multicolumn{5}{|c|}{$\begin{array}{l}\text { Definite Rheumatoid Arthritis. All were adults of } \\
\text { from } 22 \text { to } 69 \text { years of age, twelve being in the 6th, } \\
\text { and six in the } 7 \text { th decade. The majority were } \\
\text { incapacitated by severe disease, and at the time the } \\
\text { atlanto-axial displacement was diagnosed only fiven } \\
\text { were capable of light employment or light household } \\
\text { duties; eight were greatly restricted in activities and } \\
\text { unemployed or unemployable, and thirteen were } \\
\text { partially or completely bedridden. Subcutaneous } \\
\text { nodules were present in fourteen, and eighteen of } \\
\text { the } 21 \text { patients tested gave positive results in the } \\
\text { sheep cell agglutination test (Ball, 1950). Symp- } \\
\end{array}$} \\
\hline
\end{tabular}


LV

2 SPONDYLITIC PATIENTS

\begin{tabular}{|c|c|c|c|c|c|c|c|c|}
\hline \multicolumn{4}{|c|}{ Range of Spinal Movement at Diagnosis of Dislocation* } & \multicolumn{4}{|c|}{ Main Presenting Symptom } & \multirow{2}{*}{$\begin{array}{c}\text { Neurological } \\
\text { Complications } \\
\text { Present } \\
(0 \text { to }++++)\end{array}$} \\
\hline $\begin{array}{l}\text { "Atlanto- } \\
\text { Occipital" }\end{array}$ & Cervical & Dorsal & Lumbar & Pain & Deformity & Neurological & Radiological & \\
\hline Full & -Full & $0-3$ & $0-\frac{8}{8}$ & + & & & & 0 \\
\hline 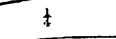 & Trace- $\frac{1}{3}$ & 0 & $\frac{1}{1}-\frac{1}{8}$ & + & & & & 0 \\
\hline 0 & 0 & 0 & 0 & & + & & & 0 \\
\hline Trace & 0-Trace & $\mathbf{0}$ & 0 & + & & & & 0 \\
\hline Trace & 0 & $\mathbf{0}$ & 0 & + & & & & +++ \\
\hline Trace & Trace & 0 & 0 & & + & & & ++ \\
\hline Trace & 0 & 0 & $\mathbf{0}$ & + & & & & 0 \\
\hline Trace & $0-\frac{1}{1}$ & 0 & 0 & + & & & & 0 \\
\hline Full & Trace- $\$$ & 0 & 0 & - & & & & -+ \\
\hline Trace & 0 & 0 & 0 & - & & & & + \\
\hline Trace & 0 & 0 & 0 & + & & & & \pm \\
\hline Trace & 0-?Trace & 0 & 0 & & & + & & +++ \\
\hline$\frac{1}{2}$ & $0-t$ & 0-Trace & 0 -Trace & + & & & . & 0 \\
\hline "?0" & Trace-t & Trace & Trace & & & & + & 0 \\
\hline Full & $0-1$ & 0 & Trace-t & + & & & & 0 \\
\hline Trace & 0-Trace & 0 & 0 & + & & & & 0 \\
\hline Trace & Trace & 0 & 0 & + & & & & 0 \\
\hline 3-Full & Trace- $-\frac{1}{4}$ & Trace-t & Trace- $t$ & + & & & & 0 \\
\hline 0 & $\mathbf{0}$ & \multicolumn{2}{|c|}{ Not Known } & + & & & & 0 \\
\hline Full & 0-Trace & 0-Trace & 0 & & & + & & +++ \\
\hline 0 & 0-Trace & 0 & 0-Trace & + & & & & \pm \\
\hline$\overline{0}$ & $\mathbf{0}$ & \multicolumn{2}{|c|}{ Not Known } & & + & & & ++- \\
\hline
\end{tabular}

* Upper cervical extension and flexion were recorded as "atlanto-occipital" movement. In the lower cervical, dorsal, and lumbar regions the ranges of flexion, extension, lateral flexion, and rotation were estimated. The minima and maxima in any of these ranges are recorded in Tables $\mathbf{V}$ and $\mathrm{VI}$.

toms of rheumatoid arthritis had been present for 10 years or less in eleven patients and for more than 20 years in five, the range in the whole group being from 5 to 46 years. In Cases 31,43 , and 44 the disease had begun at or below the age of 15 years, in Cases 36 and 37 in the late teens but in adult life in the remainder. Symptoms of cervical involvement had been present for from 7 months to 13 years in the twenty patients who could date this with reasonable accuracy. In Case 31 , a woman who was aged 30 when the displacement was diagnosed, in whom rheumatoid disease had begun at age 2 , the radiographic appearances in the cervical spine strongly suggested that this region had been affected in early childhood.

With the exception of Case 41 , in which there was a severe lumbo-dorsal flexion deformity due to osteoporosis and osteomalacia secondary to a malabsorption syndrome, none of the rheumatoid patients had serious deformity of the lower spine but almost all of them had some restriction of dorso-lumbar movement, in most cases not severe. Cervical movement was also restricted in eighteen of the 22 patients in whom it was recorded, but to 
GENERAL FEATURES OF 2

\begin{tabular}{|c|c|c|c|c|c|c|c|c|}
\hline \multirow[b]{2}{*}{$\begin{array}{l}\text { Case } \\
\text { No. }\end{array}$} & \multirow[b]{2}{*}{ Sex } & \multirow[b]{2}{*}{$\begin{array}{c}\text { Subcutaneous } \\
\text { Nodules }\end{array}$} & \multirow[b]{2}{*}{$\begin{array}{c}\text { Sheep Cell } \\
\text { Agglutination }\end{array}$} & \multirow{2}{*}{$\begin{array}{c}\text { Age at } \\
\text { Diagnosis of } \\
\text { Dislocation } \\
\text { (yrs) }\end{array}$} & \multicolumn{3}{|c|}{ Duration to Diagnosis of Dislocation (yrs) } & \multirow{2}{*}{$\begin{array}{r}\text { Disease } \\
\text { Activity } \\
\text { Presumptive } \\
\text { Time of } \\
\text { Dislocat }\end{array}$} \\
\hline & & & & & $\begin{array}{c}\text { Symptoms of } \\
\text { Rheumatoid } \\
\text { Arthritis }\end{array}$ & $\begin{array}{l}\text { Cervical } \\
\text { Symptoms }\end{array}$ & $\begin{array}{c}\text { Presumptive } \\
\text { Dislocation } \\
\text { to Diagnosis }\end{array}$ & \\
\hline 23 & $\mathbf{M}$ & 0 & + & 62 & 46 & 5 & 5 & +2 \\
\hline 24 & $\mathbf{M}$ & + & + & 62 & 11 & $?$ & $?$ & $? \frac{\sigma}{\bar{\omega}}$ \\
\hline 25 & $\mathbf{M}$ & + & + & 60 & 17 & 2 & 2 & $+\overrightarrow{\mathbb{D}}$ \\
\hline 26 & $\mathbf{M}$ & + & + & 54 & 14 & 11 & $\frac{1}{2}$ & + Q \\
\hline 27 & $\mathbf{M}$ & N.S. & N.A. & 56 & 6 & N.S. & + & + \\
\hline 28 & $\mathbf{M}$ & 0 & + & 52 & 6 & 6 & $2 \mathrm{wks}$ & 0 \\
\hline 29 & $\mathbf{M}$ & 0 & Neg. & 55 & 8 & 8 & $1 \frac{1}{2}$ & $+\vec{\omega}$ \\
\hline 30 & $\mathbf{M}$ & + & + & 61 & 7 & 7 mths & 7 mths & $+\infty$ \\
\hline 31 & $\mathbf{F}$ & 0 & Neg. & 30 & 28 & ?28 & $>6$ & ? \\
\hline 32 & $\mathbf{F}$ & 0 & N.A. & 32 & 10 & 9 & $?$ & $?$ \\
\hline 33 & $\mathbf{F}$ & 0 & + & 68 & 8 & 4 & $>3$ & $+i$ \\
\hline 34 & $\mathbf{F}$ & + & + & 69 & 6 & 1 & $<1$ & +0 \\
\hline 35 & $\mathbf{F}$ & + & N.A. & 46 & 21 & $?$ & $?$ & $?$ \\
\hline 36 & $\mathbf{F}$ & 0 & + & 32 & 15 & 2 & $?$ & ? \\
\hline 37 & $\mathbf{F}$ & 0 & + & 54 & 38 & $\begin{array}{c}4 \\
(? 40)\end{array}$ & $2 \frac{1}{2}$ & $+\frac{\tilde{\rho}}{د}$ \\
\hline 38 & $\mathbf{F}$ & 0 & Neg. & 55 & 11 & 11 & $?$ & \\
\hline 39 & $\mathbf{F}$ & + & N.A. & 61 & 8 & N.S. & $?$ & $8 \div$ \\
\hline 40 & $\mathbf{F}$ & + & + & 51 & 5 & 5 & 3 & ○ \\
\hline 41 & $\mathbf{F}$ & + & + & 51 & 14 & $>2$ & $?$ & 里 \\
\hline 42 & $\mathbf{F}$ & + & + & 56 & 22 & 12 & $?$ & ? \\
\hline 43 & $\mathbf{F}$ & + & + & 31 & 16 & 11 & 3 & $+\frac{0}{10}$ \\
\hline 44 & $F$ & + & + & 22 & 9 & $?$ & $?$ & $?$ \\
\hline 45 & $\mathbf{F}$ & + & + & 44 & 12 & 12 & $>5$ & ? $\frac{0}{3}$ \\
\hline 46 & $F$ & 0 & + & 57 & 6 & 6 & $t$ & $+\underset{\Xi}{\beth}$ \\
\hline 47 & $F$ & N.S. & $\div$ & 51 & 15 & 3 & 8 & $-\overline{0}$ \\
\hline 48 & $F$ & + & N.A. & 50 & 20 & 13 & 13 & 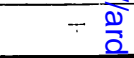 \\
\hline
\end{tabular}

a much less degree than in most of the patients with ankylosing spondylitis. The range of "atlantooccipital" movement was regarded as normal in most cases, and excessive, although painless, in Case 43 and probably so in Case 30. This contrasts with the findings in the spondylitic patients.

\section{Clinical Features and Diagnosis of Atlanto-Axial Displacement}

The clinical picture of severe atlanto-axial dislocation is characteristic and easily recognized. In less severe degrees of displacement when the diagnosis is not so obvious, symptoms including those due to neurological changes may remain unexplained unless this complication of ankylosing spondylitis or rheumatoid arthritis is considered. After the atlanto-axial displacement had been recognized in the earlier patients in this series, it was found that a fairly uniform pattern of symptoms and signs indicating a displacement could often be elicited and as a result less severe degrees of displacement were recognized more frequently.

In some severe mobile displacements, when there 
LE VI

ENTS WITH RHEUMATOID ARTHRITIS

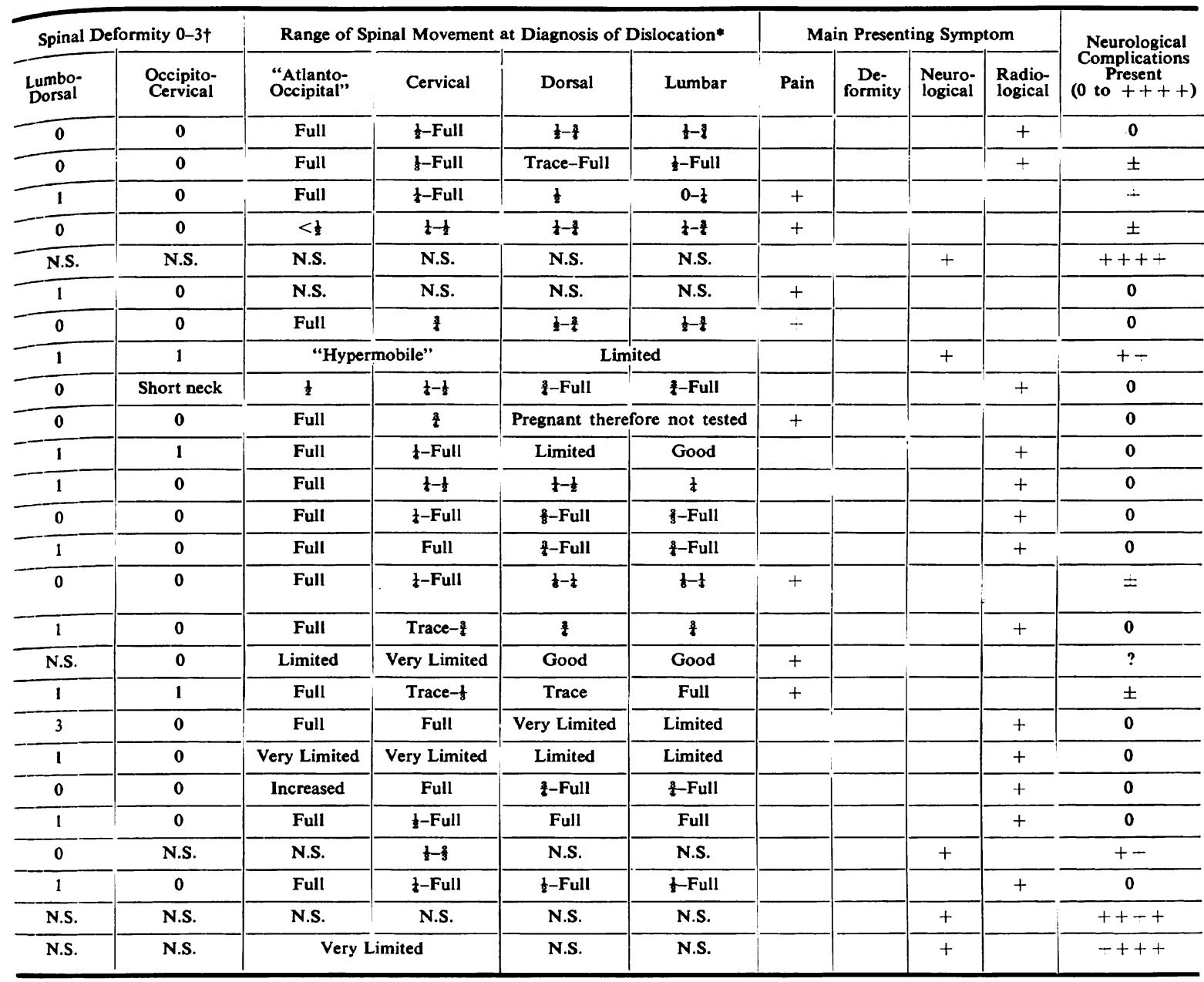

- Upper cervical extension and flexion were recorded as "atlanto-occipital" movement. In the lower cervical, dorsal, and lumbar regions, the ranges of flexion, extension, lateral flexion, and rotation were estimated. The minima and maxima in any of these ranges are recorded in Tables $V$ and VI.

was little pain or muscle spasm, it was also found that the abnormal atlanto-axial mobility could be demonstrated clinically. The palm of one hand was placed on the patient's forehead and the thumb of the other on the tip of the spinous process of the axis. The patient was then asked to relax the neck in a semi-flexed position. By pressing backwards with the palm a sliding motion of the head backwards in relation to the spine of the axis could be demonstrated. The movement was usually only appreciated by the observer, but in one patient (Case 43) was also clearly visible.
In Tables $\mathrm{V}$ and $\mathrm{VI}$ the main presenting features of the cases are indicated and illustrative case histories are included in the following account of these modes of presentation.

Pain.-This was experienced in the upper cervical, suboccipital, and occipital regions, sometimes continuously and sometimes episodically. When the pain was very severe, its area of reference extended to the temporal or even frontal regions and to the back of the eye on one or both sides. It was usually aggravated by sudden movement of the 
RADIOGRAPHIC FEATURES AND TREATMEN

\begin{tabular}{|c|c|c|c|c|c|c|c|c|c|c|c|c|}
\hline \multirow{3}{*}{$\begin{array}{l}\text { Case } \\
\text { No. }\end{array}$} & \multicolumn{4}{|c|}{ First Film } & \multicolumn{7}{|c|}{ Diagnosis Film } & \multirow{3}{*}{ 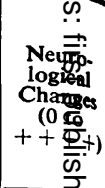 } \\
\hline & \multirow[b]{2}{*}{ Date } & \multirow{2}{*}{$\begin{array}{c}\text { Depth } \\
\text { Ant. } \\
\text { Atlanto- } \\
\text { Axial } \\
\text { Joint } \\
\text { (mm.) }\end{array}$} & \multirow[b]{2}{*}{$\begin{array}{c}\text { Inclina- } \\
\text { tion } \\
\left({ }^{(}\right)\end{array}$} & \multirow{2}{*}{$\begin{array}{l}\text { Per cent. } \\
\text { Width of } \\
\text { Original } \\
\text { Spinal } \\
\text { Canal }\end{array}$} & \multirow[b]{2}{*}{ Date } & \multirow{2}{*}{$\begin{array}{l}\text { Depth } \\
\text { Ant. } \\
\text { Atlanto- } \\
\text { Axial } \\
\text { Joint } \\
\text { (mm.) }\end{array}$} & \multicolumn{2}{|c|}{ Inclination } & \multicolumn{2}{|c|}{ Mobility } & \multirow{2}{*}{$\begin{array}{l}\text { Per cent. } \\
\text { Width of } \\
\text { Original } \\
\text { Spinal } \\
\text { Canal }\end{array}$} & \\
\hline & & & & & & & $\underset{\left({ }^{\circ}\right)}{\text { Extension }}$ & $\begin{array}{l}\text { Flexion } \\
\left({ }^{\circ}\right)\end{array}$ & $\begin{array}{c}\text { Traverse } \\
\text { (mm.) }\end{array}$ & $\underset{\left({ }^{\prime}\right)}{\text { Angular }}$ & & \\
\hline 1 & 18.10 .50 & 2 & -10 & 100 & 2.8 .56 & 4 & -9 & 0 & 3 & 9 & 90 & \\
\hline 2 & 8.6 .55 & 4 & -3 & 90 & 8.5 .57 & 8 & +10 & +12 & $\mathbf{0}$ & 2 & 75 & $\xi^{2}$ \\
\hline 3 & - & & & & 20.9 .55 & 12 & & +13 & N.A. & N.A. & 35 & 8 \\
\hline 4 & - & & & & 24.10 .56 & 4 & -6 & -4 & 0 & 2 & 90 & $\bar{q}$ \\
\hline 5 & 22.7 .53 & $<2$ & -8 & 100 & 15.9 .55 & 16 & & +18 & N.A. & N.A. & 25 & $+\frac{b^{+}}{2}$ \\
\hline 6 & - & & & & $7.6 .57^{*}$ & \multicolumn{5}{|c|}{ Not measurable } & & \\
\hline 7 & - & & & & 20.3 .56 & 15 & & 0 & N.A. & N.A. & 40 & Q \\
\hline 8 & 3.4 .54 & 1 & -10 & 100 & 4.7 .56 & 4 & -10 & +6 & 2 & 16 & 90 & 0 \\
\hline 9 & - & & & & 20.7 .56 & 7 & -8 & +23 & 7 & 31 & 75 & $\overrightarrow{+\ddagger}$ \\
\hline 10 & 8.8 .47 & 2 & -6 & 100 & 13.9 .56 & 6 & -12 & -5 & 2 & 7 & 80 & $\frac{\pi}{2}$ \\
\hline 11 & 24.1 .55 & 9 & +3 & 70 & 30.5 .56 & 10 & -5 & +4 & 5 & 9 & 70 & o \\
\hline 12 & 8.2 .55 & 6 & +27 & 55 & 26.10 .55 & 10 & -30 & N.A. & N.A. & N.A. & 30 & -फ़्ड़ \\
\hline 13 & - & & & & $24.5 .57^{*}$ & 2 & -32 & -12 & 1 & 20 & 100 & 20 \\
\hline 14 & 17.10 .56 & 1 & -15 & 100 & 13.12 .56 & 3 & -16 & o & 2 & 16 & 90 & 흘올 \\
\hline 15 & - & & & & 12.11 .58 & 9 & -6 & +11 & 4 & 17 & 70 & कำ \\
\hline 16 & 30.6 .54 & $<1$ & -17 & 100 & 22.1 .59 & 5 & -12 & -5 & 2 & 7 & 90 & $0^{0}$ \\
\hline 17 & 26.3 .57 & 3 & +5 & 90 & 25.4 .57 & 3 & -15 & +17 & 1 & 2 & 95 & 00 \\
\hline 18 & 18.4 .57 & $2 \cdot 5$ & -17 & 95 & 21.11 .57 & $5 \cdot 5$ & -30 & -20 & 3 & 10 & 75 & 0 \\
\hline 19 & - & & & & 1945 & \multicolumn{6}{|c|}{ Not known } & क़् \\
\hline 20 & 21.9 .53 & 3 & -15 & 95 & $26.11 .54 \dagger$ & 17 & -6 & +21 & 5 & 27 & 25 & $++\bar{p}$ \\
\hline 21 & 24.4 .57 & 1.5 & -3 & 100 & 12.9 .58 & 6 & -11 & N.A. & N.A. & N.A. & 70 & \pm 3. \\
\hline 22 & - & & & & 1947 & N.A. & N.A. & N.A. & N.A. & N.A. & N.A. & $1 \%$ \\
\hline $\begin{array}{l}\text { head or } \\
\text { patients } \\
\text { if their } \\
\text { in their } \\
\text { inwards }\end{array}$ & $\begin{array}{l}\text { by the ja } \\
\text { tated th } \\
\text { eads we } \\
\text { hands, } \\
\text { Pain }\end{array}$ & $\begin{array}{l}\text { rring of } \\
t \text { such jo } \\
e \text { steadie } \\
\text { if they } \\
f \text { this } c\end{array}$ & $\begin{array}{l}\text { bus or } \\
\text { rneys } \\
\text { by cra } \\
\text { sat on } \\
\text { aracter }\end{array}$ & $\begin{array}{l}\text { ar ride. } \\
\text { re only } p \\
\text { lling thei } \\
\text { ide seats } \\
\text { was grea }\end{array}$ & $\begin{array}{l}\text { Some } \\
\text { ossible } \\
r \text { chins } \\
\text { facing } \\
\text { tly in- }\end{array}$ & $\begin{array}{l}\text { creased } \\
\text { anaesth } \\
\text { of activ } \\
\text { movem } \\
\text { with a }\end{array}$ & $\begin{array}{l}\text { in one } \\
\text { esia, and } \\
\text { e exercis } \\
\text { ent of th } \\
\text { nkylosing }\end{array}$ & $\begin{array}{l}\text { patient } \\
\text { in ano } \\
\text { es aimed } \\
\text { head a } \\
\text { spond }\end{array}$ & $\begin{array}{l}\text { (Case } 1 \\
\text { her (Cas } \\
\text { at increa } \\
\text { d neck. } \\
\text { litis the }\end{array}$ & $\begin{array}{l}\text { 7) after } \\
\text { 8) by } \\
\text { sing the } \\
\text { In fou } \\
\text { pain }\end{array}$ & $\begin{array}{l}\text { general } \\
\text { a course } \\
\text { range of } \\
\text { patients } \\
\text { was not }\end{array}$ & 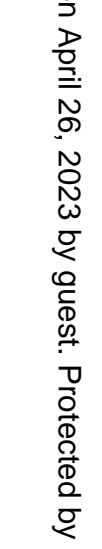 \\
\hline
\end{tabular}


[S VII

2 PATIENTS WITH ANKYLOSING SPONDYLITIS

\begin{tabular}{|c|c|c|c|c|c|c|c|c|}
\hline \multirow{3}{*}{ Treatment } & \multirow{3}{*}{ Clinical Result } & \multirow{3}{*}{ Date } & \multicolumn{5}{|c|}{ Last Film } & \multirow{3}{*}{$\begin{array}{l}\text { Per cent. } \\
\text { Width of } \\
\text { Original } \\
\text { Spinal } \\
\text { Canal }\end{array}$} \\
\hline & & & \multirow{2}{*}{$\begin{array}{c}\text { Depth } \\
\text { Ant. } \\
\text { Atlanto- } \\
\text { Axial } \\
\text { Joint } \\
\text { (mm.) }\end{array}$} & \multicolumn{2}{|c|}{ Inclination } & \multicolumn{2}{|c|}{ Mobility } & \\
\hline & & & & $\begin{array}{l}\text { Extension } \\
\left({ }^{\circ}\right)\end{array}$ & $\begin{array}{l}\text { Flexion } \\
\left({ }^{c}\right)\end{array}$ & $\begin{array}{l}\text { Traverse } \\
\text { (mm.) }\end{array}$ & $\underset{\left({ }^{\circ}\right)}{\text { Angular }}$ & \\
\hline None & Remission with aspirin & 16.3 .57 & 4 & -10 & 0 & 3 & 10 & 95 \\
\hline Collar & Excellent relief & 28.1 .59 & 4 & +4 & +9 & 0 & 5 & 90 \\
\hline $\begin{array}{l}\text { Skull traction. Occipito-cervical } \\
\text { fusion }\end{array}$ & Complete relief & 7.8 .56 & 4 & -25 & -25 & 0 & 0 & 80 \\
\hline None. Defaulted & - & - & & & & & & \\
\hline Traction. Fusion & $\begin{array}{l}\text { Complete symptomatic relief and } \\
\text { almost complete neurological } \\
\text { recovery }\end{array}$ & $\begin{array}{r}6.10 .56 \\
4.6 .59\end{array}$ & $\begin{array}{l}6 \\
6\end{array}$ & -12 & $\begin{array}{l}-12 \\
-12\end{array}$ & 0 & $\mathbf{0}$ & $\begin{array}{l}70 \\
70\end{array}$ \\
\hline Traction. Plaster $\rightarrow$ Plastic collar & $\begin{array}{l}\text { Symptoms relieved and almost } \\
\text { complete neurological recovery }\end{array}$ & 29.1 .59 & $3 \cdot 5$ & -21 & N.A. & N.A. & N.A. & 95 \\
\hline $\begin{array}{l}\text { No symptoms when diagnosed. } \\
\text { Collar during physical treatment }\end{array}$ & - & 9.8 .56 & 15 & 0 & 0 & 0 & 0 & 40 \\
\hline None & Intermittent pain & 5.1 .60 & 2 & -12 & -7 & 2 & 5 & 100 \\
\hline Traction. Fusion & Mild residual pyramidal signs & 23.10 .56 & 5 & -14 & -14 & 0 & $\mathbf{0}$ & 80 \\
\hline Traction. Fusion & Complete regression of cord signs & 24.4 .57 & 4 & -15 & -15 & $\mathbf{0}$ & $\mathbf{0}$ & 80 \\
\hline Traction. Fusion & Complete relief & 6.10 .56 & 2 & -8 & -8 & 0. & $\mathbf{0}$ & 100 \\
\hline Traction. Fusion & $\begin{array}{l}\text { Minimal residual cervical pain and } \\
\text { neurological changes }\end{array}$ & 3.10 .56 & 4 & -1 & -1 & $\mathbf{0}$ & $\mathbf{0}$ & 90 \\
\hline Traction. Plaster. Collar & Complete relief & 30.3 .60 & $1 \cdot 5$ & -35 & -17 & $0 \cdot 5$ & 18 & 100 \\
\hline Serial plasters. Collar & $\begin{array}{l}\text { Recurrence of deformity but little } \\
\text { pain after removal }\end{array}$ & 10.4 .58 & $3 \cdot 5$ & -17 & -10 & $2 \cdot 5$ & 7 & 85 \\
\hline$\underset{\text { "Hallar } \rightarrow \text { from 5th to } 12 \text { th wk }}{\text { Traction }} \rightarrow$ Fusion. & Complete relief & 21.7 .59 & $2 \cdot 5$ & -4 & -4 & 0 & 0 & 90 \\
\hline Collar & Complete relief & 21.4 .60 & $3 \cdot 0$ & -21 & -4 & 2 & 17 & 95 \\
\hline Traction. Fusion & Complete relief & - & & & & & & \\
\hline Cardboard $\rightarrow$ Plastic collar & Pain relieved & 25.2 .60 & $7 \cdot 0$ & -20 & -17 & 0.5 & 3 & 70 \\
\hline $\begin{array}{c}\text { Traction } \rightarrow \text { Immobilization for } 9 \\
\text { mths. Fusion, } 1949\end{array}$ & $\begin{array}{l}\text { Recurrence of symptoms } 18 \mathrm{mths} \\
\text { after immobilization. Relief after } \\
\text { fusion }\end{array}$ & 24.4 .57 & 19 & 0 & 0 & 0 & 0 & 30 \\
\hline None & Tetraplegia. Death & - & & & & & & \\
\hline Iraction. Fusion & $\begin{array}{l}\text { Complete relief of pain and subsi- } \\
\text { dence of neurological symptoms }\end{array}$ & $22.9 .58 \S$ & $1 \cdot 5$ & -21 & N.A. & N.A. & N.A. & $>90$ \\
\hline $\begin{array}{l}\text { Traction. Laminectomy C.1. } \\
\text { Fusion }\end{array}$ & Mild neurological residua & 26.4 .54 & 12 & +20 & N.A. & N.A. & N.A. & $30_{+}^{+}$ \\
\hline
\end{tabular}

Estimated. Partial operative removal of posterior arch of atlas.

$\S$ On traction before fusion. Position unaltered on 30.12 .58 after union of graft, but film not satisfactory for measurement.

relieved by radiotherapy. On the other hand correction and stabilization of the displacement resulted in complete relief of symptoms.

Case 8. Ankylosing Spondylitis.-A male cranedriver aged 44 years first attended in April, 1954, with advanced ankylosing spondylitis of 14 years' duration. He had a total flexion deformity of $30^{\circ}$ and his lumbar and dorsal spine was rigid. Although the lower cervical spine had greatly restricted movement there was a full range at the "atlanto-occipital" joint. Radiographs of the spine showed changes typical of ankylosing spondylitis 
and the relations of the atlas to the axis were normal.

His main disability arose from a painful restriction of hip movement, and he was given radiotherapy to the hips with good relief of symptoms.

He next attended in September, 1955, having developed a severe pain in the neck 4 months previously. There was now only a trace of cervical movement. Radiotherapy on this occasion failed to relieve his symptoms and within one month he was complaining of much pain in the back of the head. During the next 5 months, whilst in hospital having physical treatment, his symptoms were intermittent and it was noted on discharge that there was increased mobility in the cervical spine. Although he became free from pain this recurred within a month of his leaving hospital and he found that his head seemed to slip forwards towards the end of the day. Radiographs revealed a 4-mm. separation of the odontoid from the anterior arch of the atlas on flexion of the neck, which decreased to $2 \mathrm{~mm}$. on extension of the head. There was also considerable angular mobility of the atlas on the axis (Table VII).

He was warned of the possible dangers of violent head movements, particularly flexion, and was kept under observation as an out-patient, but was given no specific treatment for the displacement. He has continued to have episodes of severe upper cervical and occipital pain lasting weeks to months with intervening periods of several months of virtually complete freedom. When riding on buses he always chooses a side seat, since jogging movements of the head, particularly in an antero-posterior direction invariably aggravate and may precipitate the pain. Judged from the most recent radiographs taken $2 \frac{1}{2}$ years after the first diagnosis, the displacement has not increased in degree and the atlantoaxial mobility appears to be slowly decreasing (Table VII).

COMmENT.-The symptoms of atlanto-axial displacement in this patient were intermittent. In him and in three others, Cases 4, 5, and 11 (Table V), they were misinterpreted as evidence of reactivation of the spondylitis; in retrospect it is not surprising that radiotherapy failed to relieve them. An increase in movement of the neck and aggravation of the pain followed physical treatment; this case illustrates the possible dangers of intensive exercises in a patient with grossly restricted movement of the cervical spine.

Case 17. Ankylosing Spondylitis.-A housewife aged 55 years first had symptoms of ankylosing spondylitis at age 30 . Over the years, as pain and stiffness spread up the spine, she developed an increasing flexion deformity. Her cervical spine was greatly restricted in motion from age 50 . In spite of this progression her general health remained good and she led an active life with decreasing pain as her spine became more limited in motion. When she was 53 years old she first noted mild pains in her neck radiating up the back of her head to the vertex on jarring. About the same time she developed symptoms of peptic ulceration and later of pyloric stenosis for which after a year and a half she had a partial gastrectomy. Within
3 months symptoms returned and pyloroplasty was performed. Evidence of steatorrhoea was noted after the operations; her diet was generally deficient.

The upper cervical and occipital pain increased after the first operation and became even worse after the second; the pain was so severe when riding in vehicles that she supported her head with both hands. Her neck became almost rigid, the head being flexed on the neck. She was unable to restore her normal posture and any attempt to do so passively greatly increased the pain. Shortly after the second operation she developed paraesthesiae in the extremities, painful swelling of the feet and knees and, later, pitting oedema of the ankles. Examination at this time revealed an anaemic emaciated middle-aged woman in considerable distress. She stood with difficulty with an overall flexion deformity of $25^{\circ}$, due partly to the slight increase in dorsal kyphosis, but mainly to flexion of the head upon the neck. Her chin was rotated $10^{\circ}$ to the right and there was slight downward tilting of the left side of the head. The spine was rigid apart from the upper cervical region where there was a trace of movement in all directions which caused severe occipital pain.

The liver and spleen were enlarged and there was evidence of a predominantly sensory peripheral neuropathy mainly affecting the lower limbs.

Radiographs (Table VII) revealed considerable $\left(17^{\circ}\right)$ forward tilting of the atlas upon the axis, but only $3 \mathrm{~mm}$. separation of the odontoid from the anterior arch of the atlas in flexion, and these decreased to $15^{\circ}$ and $2 \mathrm{~mm}$. respectively on extension.

The pain was so intolerable that after her multiple nutritional deficiencies had been corrected skull traction was instituted and this was followed by immediate and almost complete relief of pain. Occipito-cervical fusion was performed with complete relief of cervical symptoms.

COMMENT.-This case illustrates the severe symptoms which may arise from minimal atlanto-axial displacement and the hazards to which such patients are exposed when under general anaesthesia.

Case 40. Rheumatoid Arthritis.-A housewife developed a generalized polyarthritis involving many limb joints and the cervical spine at age 46 , and 3 years later, after two incomplete remissions, there was a deterioration in general health and joint condition so that she was reduced almost to a bed-chair life.

At the age of 51, 9 months before she was seen, when dozing in a chair she "nodded off" and as she did so felt a click in her neck. Her neck immediately became very painful and stiff, her head being flexed on the neck. This state of affairs continued for 6 months until, when she was reaching up to dislodge a fly, her head suddenly "slipped back" with relief of pain and return of movement. The neck had given no further trouble until one month before admission when, whilst being assisted in bed, she had fallen back on to the pillows with her husband's arm behind her neck. Again there was a click followed by sub-occipital pain which persisted and 
was accompanied by a grinding sensation on moving the head, particularly into flexion.

On examination she was found to be anaemic and emaciated. She had severe destructive rheumatoid arthritis affecting almost all the limb joints with subcutaneous nodules over the elbows, lymphadenopathy, and splenomegaly. The plantar responses were equivocal, being difficult to interpret owing to the deformity of the feet; otherwise the nervous system appeared normal.

She had an almost fixed dorsal kyphosis of moderate severity and normal movement of the lumbar spine. She held her head slightly flexed on the neck. Movement of the head upon the neck was full but there was restriction of movement of the lower cervical spine. Movement was accompanied by pain in the neck and suboccipital regions and by audible crepitus.

Radiographs revealed a mobile forward subluxation of the atlas upon the axis with a 5-mm. separation of the dens from the anterior arch of the atlas in flexion. The third, fourth, and fifth vertebrae were each subluxated forwards.

She was provided with a padded cardboard collar and was started on steroid therapy. There was satisfactory relief of symptoms.

Comment.-This patient's course suggests that the atlanto-axial displacement followed the trivial event of "nodding off" in a chair, and illustrates the dangerous mechanical instability of the cervical spine commonly present in severe rheumatoid disease (Ball, 1958; Sharp, Purser, and Lawrence, 1958). In the management of such patients we now assume that the cervical spine is excessively vulnerable to mechanical stress and take steps to protect them from this.

Occipito-Cervical Deformity.-In the patients with rheumatoid arthritis, deformity was not a prominent feature and was never the presenting manifestation. Sometimes the neck appeared foreshortened and the head carried forwards, but in general, and particularly in females when the occipito-cervical contour was obscured by the hair, the outward appearance was normal.

In ankylosing spondylitis, however, deformity was common. There were three components to this deformity. First, tilting forward of the atlas upon the axis fixed the head in some degree of flexion and as a result decreased an already diminished height of vision. Six patients complained of difficulty in shaving as a result of the chin being tucked into the neck. Many patients described a sensation of "falling forwards" of the head. Secondly, a forward displacement of the head flattened the normal contour of the occipital region (Fig. 3a, Case 7). Thirdly, some rotation and tilting of the head was usually present through asymmetrical slipping of the facets (Fig. 3b). In one man with a complete rotary dislocation of the atlas (Case 6), the head was fixed in full rotation to the right.

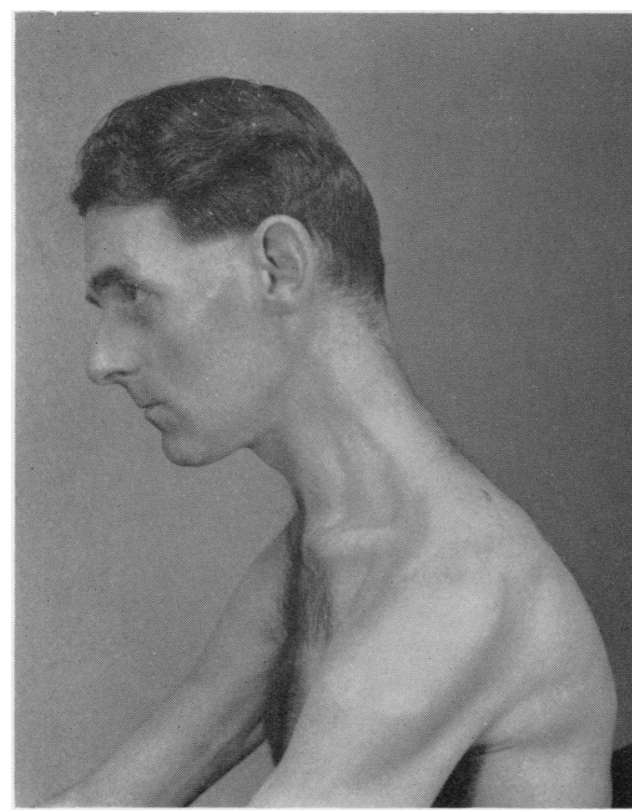

(a)

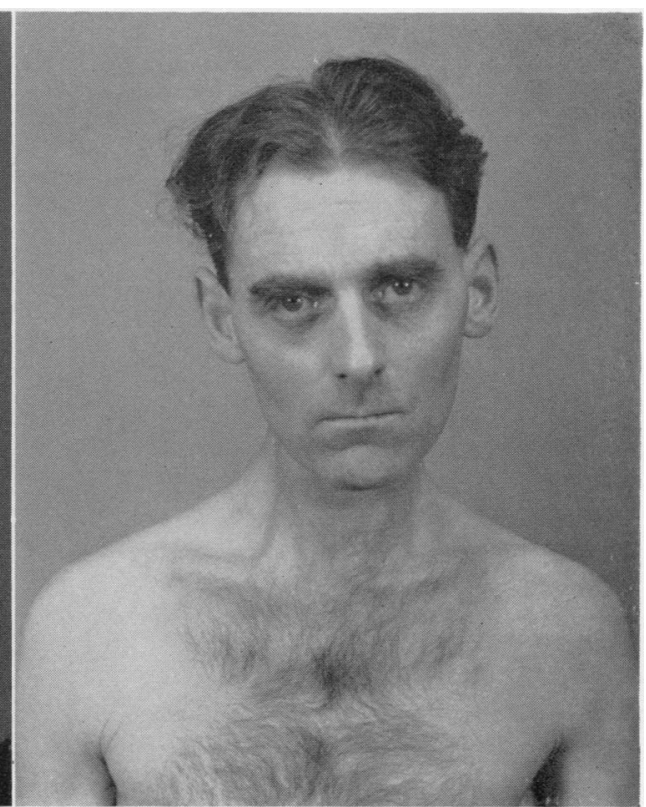

(b)

Fig. 3.-Casis 7; the occipito-cervical curve is flattened and there is mild torticollis. 
Case 3. Ankylosing Spondylitis.-A male cotton worker presented with severe ankylosing spondylitis at the age of 39 years. He had first noted low back pain when 32 years old. After some 12 months his general health deteriorated and he developed an increasing stoop and a rigid spine. Within a year his head began to "fall forwards" by degrees, with an associated almost constant dull frontal headache relieved by supporting his head with his hands. There was suboccipital pain on any attempted movement of the head. He noted increasing difficulty in shaving under his chin.

So extreme was his ultimate deformity that he was unable to open his mouth fully as his chin came in contact with his sternum and it was mainly on account of his increasing difficulty in eating that his general practitioner referred him to hospital.

When he stood (Fig. 4a) his neck was at $10^{\circ}$ below the horizontal. A minor degree of rotation of the head to the right and tilting to the left was also present. The whole spine was rigid and there was some limitation of movement of the hips. The chest expansion was reduced and there was evidence of bronchiectasis of the lower lobe of the right lung. The knee jerks were abnormally brisk, but there was no other neurological abnormality.

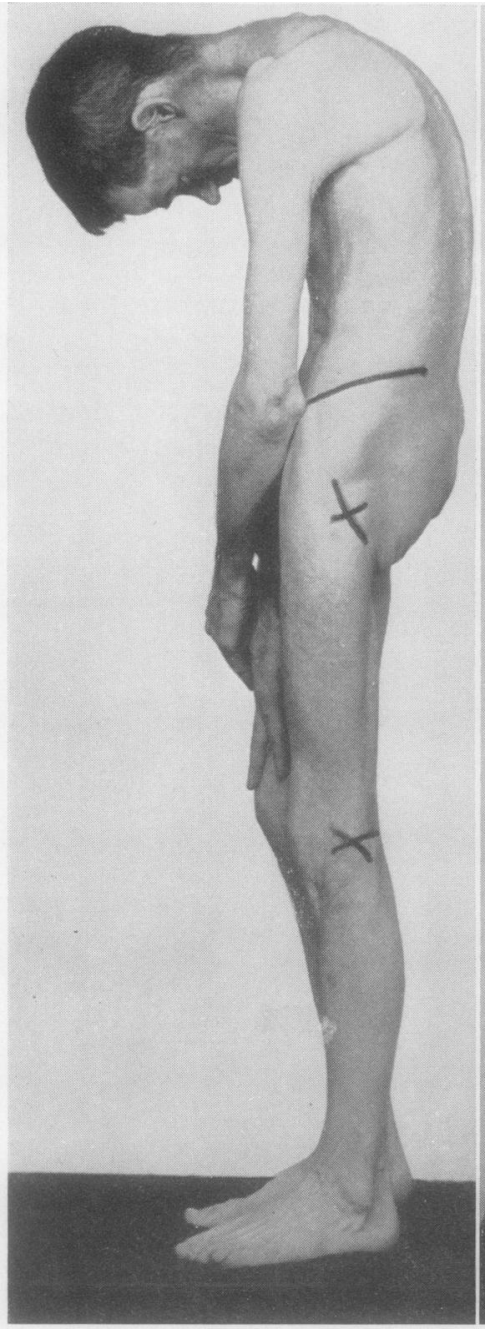

(a)

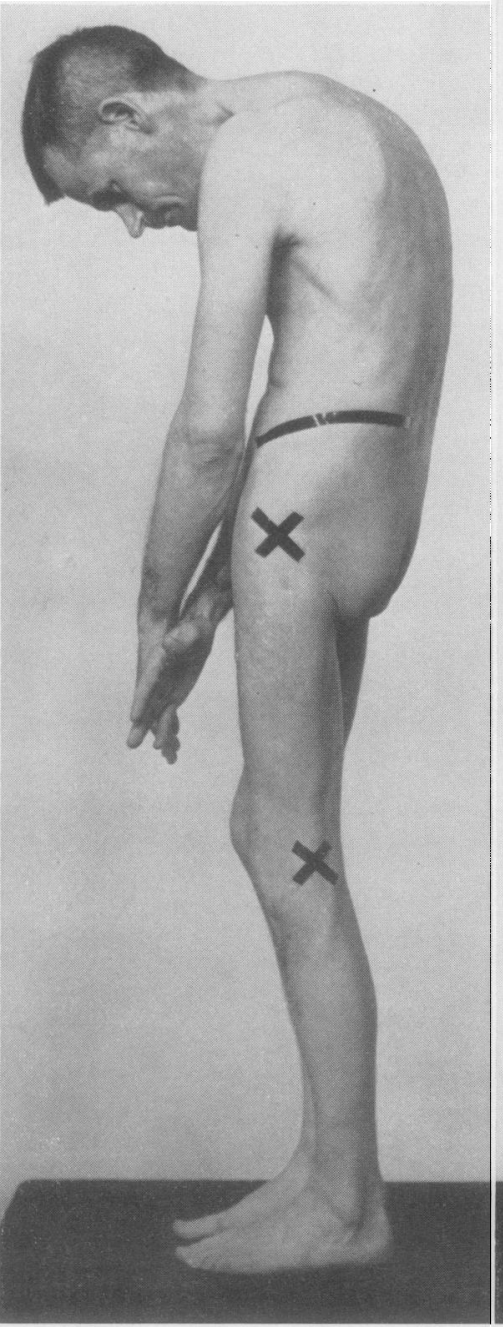

(b)

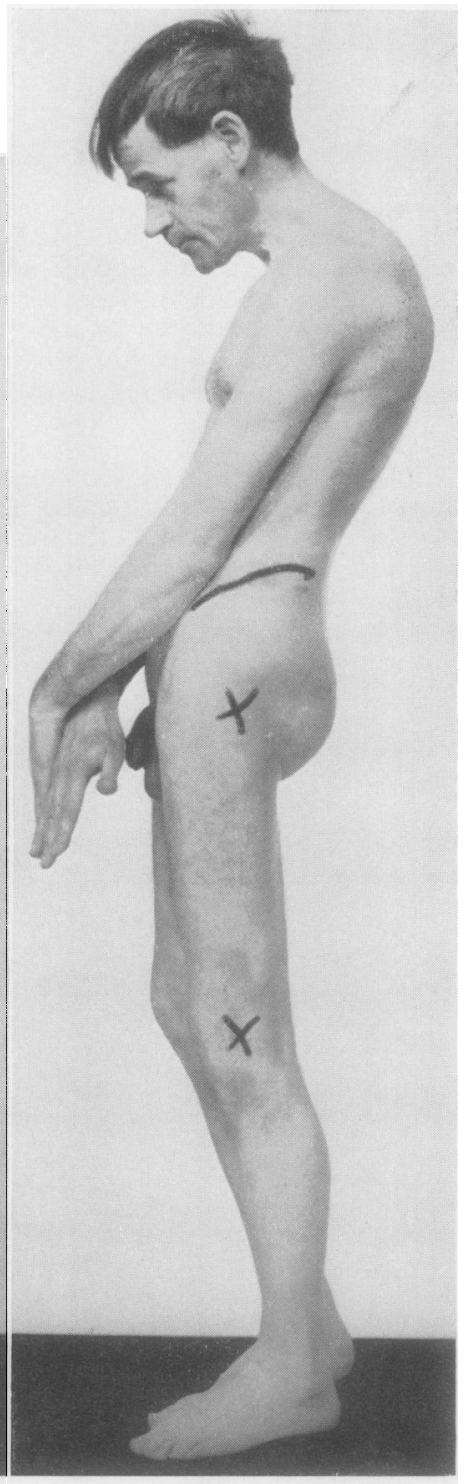

(c)

Fig. 4.-Case 3.

(a) Before treatment; (b) After occipito-cervical fusion; (c) After lumbar osteotomy. 


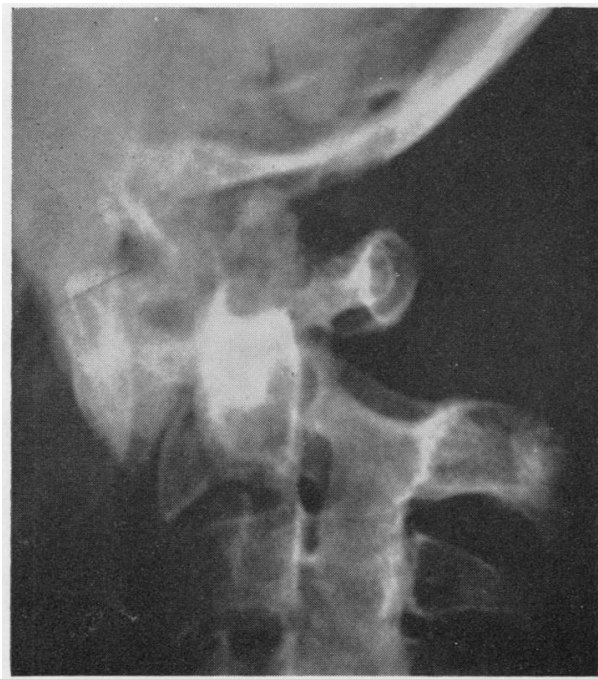

(a)

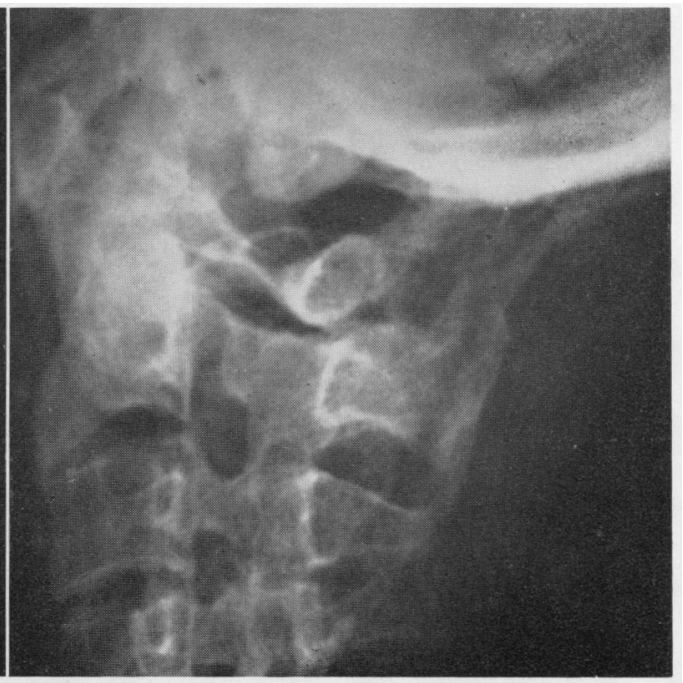

(b)

Fig. 5.-Case 3.

(a) Before treatment, showing severe atlanto-axial dislocation; (b) After skull traction and occipito-cervical fusion.

Radiographs (Fig. 5a, Table VII) disclosed gross forward displacement and forward angulation of the atlas on the axis. The antero-posterior diameter of the spinal canal was reduced by about two-thirds. There was also a minor degree of fixed forward displacement of the seventh cervical on the first thoracic vertebrae.

Traction by skull calipers was instituted, and after 18 days the forward angulation of the atlas had been overcome and the distance between the dens and the anterior arch of the atlas had been reduced from 12 to $4 \mathrm{~mm}$. 2 weeks later occipito-cervical fusion was performed. The patient's post-operative course was complicated by a sore on the forehead from the pressure of the plaster and by a brief flare-up of arthritis in the right hip joint. Although special attention was paid to the retention of mobility of the limb joints by supervised exercises, there was some decrease in the range of motion of both hips and the shoulders. Fusion occurred with the atlas in its corrected position (Fig. $5 b$ ).

In spite of maintaining good correction of the position of the head, the tip of the chin was still only 2 in. from the chest, and the face was still directed downwards when he was standing (Fig. 4b). Further correction of his posture was obtained by lumbar osteotomy, some $45^{\circ}$ of extension being achieved at the level of the disk between the third and fourth lumbar vertebrae. 2 years after his first attendance he was free from pain and his function had been greatly improved (Fig. 4c).

COMMENT.-Reduction of the displacement and occipito-cervical fusion were indicated in this patient both on account of the disability due to the exceptionally severe deformity and also because of the danger of serious cord damage from trivial injury with an unstable atlantoaxial displacement of such magnitude.
Case 7. Ankylosing Spondylitis.-A 37-year-old industrial chemist first attended in March, 1956, suffering from advanced ankylosing spondylitis of 14 years' duration. His main disability arose from the hip joints which over the previous year had become very painful and grossly restricted in motion. He had a severe lumbo-dorsal flexion deformity, and his spine was almost painless but rigid apart from a trace of motion in the cervical region.

The attitude of his head (Fig. 3) strongly suggested atlanto-axial subluxation. His head was flexed and displaced forward on the neck with loss of the normal occipito-cervical curve, slight rotation of the jaw to the left, and downward tilting of the head to the right. Radiographs taken in attempted flexion and extension of the neck (Fig. 6, overleaf; Table VII) revealed that he had a stable atlanto-axial displacement; the only movements remaining were traces at the atlanto-occipital joints and between the second and third vertebrae.

The atlanto-axial displacement was causing no symptoms at this time and there were no neurological abnormalities, but inquiry revealed that for a period of about 2 months 3 years previously he had had severe lancinating pains from the upper cervical region to the vertex which had subsided without special treatment.

He was fitted with a block leather collar which he wore for some months whilst receiving physical therapy in hospital which, combined with $x$-ray therapy to the hips, resulted in some improvement. He then discarded the collar and since discharge from hospital has led an active life for 3 years with no symptoms from the subluxation.

CoMment.-From the patient's history it appeared that the atlanto-axial displacement had become fixed spontaneously over a period of some 2 months. As 


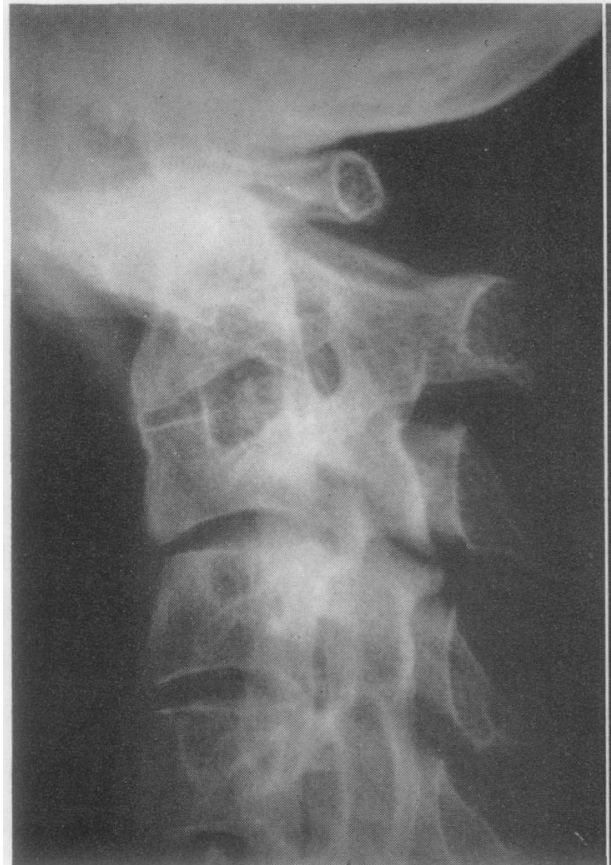

(a)

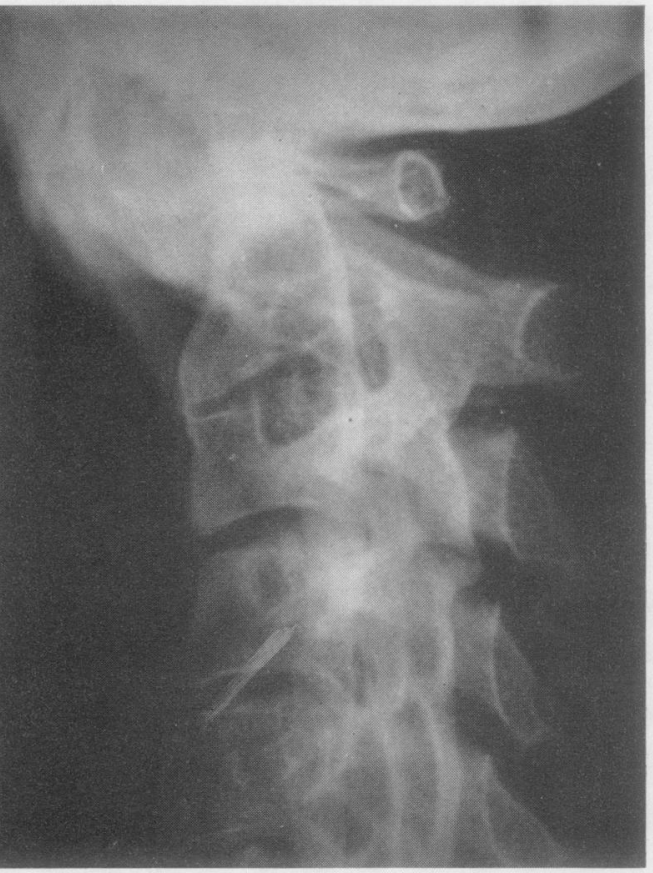

(b)

Fig. 6-Case 7 ; radiographs: $(a)$ in flexion, $(b)$ in extension

There is a trace of movement at the atlanto-occipital joints and of the 3 rd on the 4 th cervical vertebra; the atlanto-axial displacement is fixed.

the displacement was producing no symptoms and was stable and therefore appeared unlikely to produce cord damage, no treatment was thought to be indicated other than the use of a supporting collar in circumstances in which the neck was likely to be subjected to unusual mechanical stresses.

Presentation as an Unexplained Neurological Disorder.-Serious neurological complications from atlanto-axial displacements are probably rare in ankylosing spondylitis and rheumatoid arthritis, but in both conditions the presenting symptoms of the displacement may be those of disturbances of spinal cord function. The neurological syndromes produced may be bizarre and their cause obscure unless the possibility of atlanto-axial displacement is specifically considered. These neurological complications are to be dealt with in detail in a separate publication (Sharp and Purser, 1961), but the following case reports illustrate two of the more severe examples encountered in such patients.

Case 12. Ankylosing Spondylitis.-A 64-year-old male clerk attended hospital in January, 1955, complaining of painful stiffness of the neck of 7 years' duration. For 3 years his head had been sinking forward on to his chest. He was found to have advanced ankylosing spondylitis, with a rigid spine apart from a few degrees of residual cervical movement. In addition to the changes of ankylosing spondylitis, the radiograph of the cervical spine (Fig. 7a, opposite) disclosed forward subluxation of the seventh cervical on the first thoracic vertebra, and subluxation of the atlas on the axis was in fact also present, although it was not observed at the time.

Over the next few months the patient found increasing difficulty in shaving under his chin because of a progressive forward sinking of his head, and he also noted occasional involuntary twitching of his back muscles. In October, 1955, over a few days he developed increasing weakness of the right hand and arm, involuntary twitchings of the right shoulder muscles, mild flexor spasms in the right leg, and disturbances of touch and temperature sensibility in the left hand. On three occasions when about to bend down he "collapsed like a rag doll".

When he was admitted to hospital the neurological signs suggested a partial transection of the upper cervical cord mainly on the right side. During the first few days in hospital the weakness of the right arm progressed to almost complete paralysis and he developed such great difficulty in coughing and breathing that he required treatment for a week in a Drinker respirator. Radiographs of the cervical spine now showed that, although the vertebral displacement was unaltered in the lower cervical spine, the atlas had slipped forwards a further $4 \mathrm{~mm}$. (Table VII).

After an hour or so in the respirator in which his neck was in a position of maximum extension, there was 


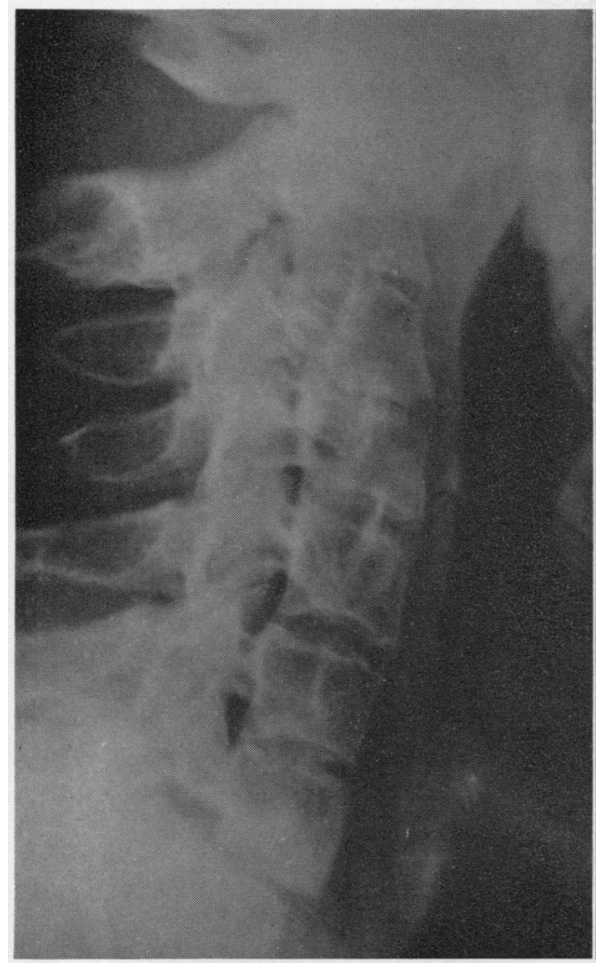

(a)

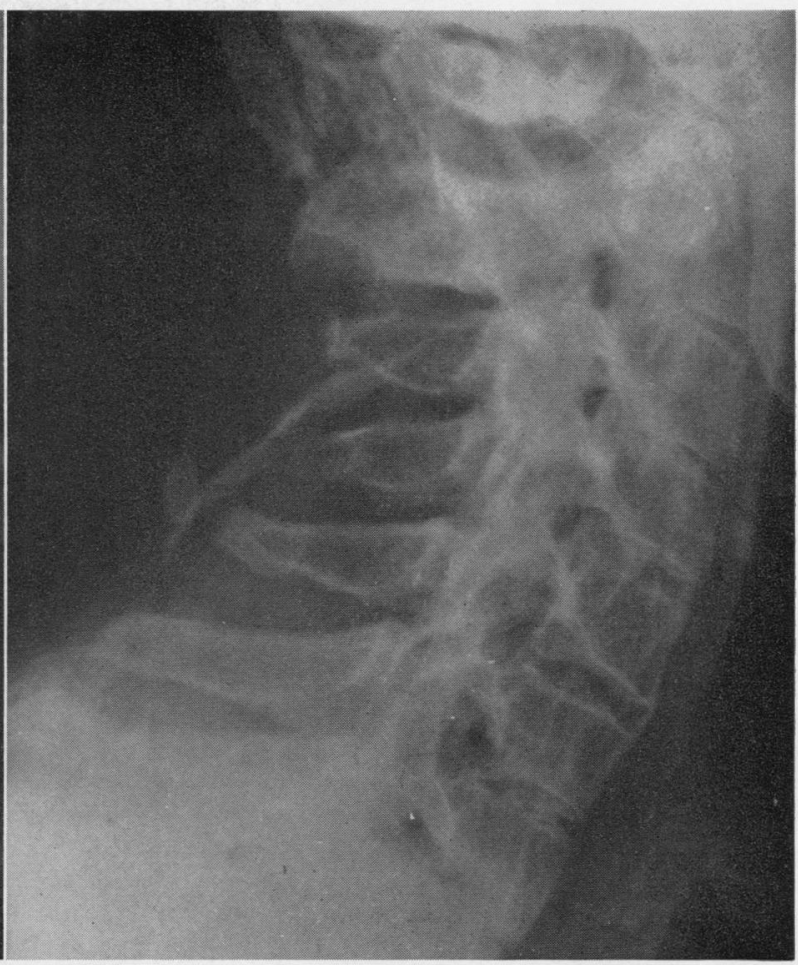

(b)

Fig. 7.-Case 12

(a) Before treatment, showing forward displacement of the atlas on the axis and of the 7th cervical on the 1st thoracic vertebra; (b) After skull traction and occipito-cervical and cervico-dorsal fusion.

a distinct and sustained improvement in the neurological picture. Subsequently, after reduction of the displacements and fusion of both the upper cervical and cervico-dorsal region (Fig. $7 b$ ), his neck became virtually painless and there was an almost complete regression of the neurological signs.

COMment.-This case illustrates three points: first, the ease with which an atlanto-axial displacement may be missed in examining radiographs, particularly when other changes are present, notably a more obvious displacement lower in the neck; secondly, how, after a long period, severe neurological complications may rapidly supervene in a patient with an unstable displacement; and thirdly, the excellent recovery of neurological function commonly observed after reduction and stabilization of the displacement.

Case 47. Rheumatoid Arthritis.-A single woman aged 51 years developed severe progressive rheumatoid arthritis at age 35 . Early in 1954 at age 48 she had experienced transitory episodes of pain in the neck and, after sitting with the head bent forwards as in sewing, aching in the sub-occipital region which would pass off 10 to 15 minutes after bringing her head up. The sub- occipital pain steadily increased in severity, and shortly before Christmas, 1955, it radiated to the right temporal region. She now experienced a constant unpleasant sensation as if herr head and neck were clasped in a vice, loss of temperature sensibility in the left foot, numbness and tingling in the left thigh and hand, and relief of the previously severe pain from her left hip. A few weeks later she developed precipitancy of micturition. In April, 1956, her right hand and arm became weak and position sense was lost. One month later the right leg became weak and heavy, but she was able to walk until an episode in which her left leg and arm "gave way". This occurred as she was making her way to an ambulance which was to convey her to hospital for a herniorrhaphy which fortunately passed without incident.

When admitted to hospital in July, 1956, she stated that she was sure that something had developed in addition to the arthritis "for I feel dreadful all over". Her state of general health was good. Apart from precipitancy of micturition and an inability to expel faeces from the rectum there were no visceral abnormalities. Severe destructive changes were present in almost all the joints and movement of the neck was painful, but the rheumatoid process appeared to be inactive and the erythrocyte sedimentation rate was only $5 \mathrm{~mm} . / \mathrm{hr}$ (Westergren). 
Interpretation of the neurological changes was difficult on account of the joint disease. There was general muscle wasting and weakness maximal on the right side, with pyramidal signs including extensor plantar responses in both lower limbs. Vibration sense was absent in the legs and sensibility to pin-prick and light touch as well as temperature discrimination were impaired or absent over the left leg and left half of the trunk up to the level

RADIOGRAPHIC FEATURES AND TREATMENT

\begin{tabular}{|c|c|c|c|c|c|c|c|c|c|c|c|c|}
\hline \multirow{3}{*}{$\begin{array}{l}\text { Case } \\
\text { No. }\end{array}$} & \multicolumn{4}{|c|}{ First Film } & \multicolumn{7}{|c|}{ Diagnosis Film } & \multirow{3}{*}{ 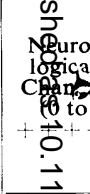 } \\
\hline & \multirow{2}{*}{ Date } & \multirow{2}{*}{$\begin{array}{l}\text { Depth } \\
\text { Ant. } \\
\text { Atlanto- } \\
\text { Axial } \\
\text { Joint } \\
\text { (mm.) }\end{array}$} & \multirow{2}{*}{$\begin{array}{l}\text { Inclina- } \\
\text { tion } \\
\left({ }^{\circ}\right)\end{array}$} & \multirow{2}{*}{$\begin{array}{c}\text { Per cent. } \\
\text { Width of } \\
\text { Original } \\
\text { Spinal } \\
\text { Canal }\end{array}$} & \multirow[b]{2}{*}{ Date } & \multirow{2}{*}{$\begin{array}{c}\text { Depth } \\
\text { Ant. } \\
\text { Atlanto- } \\
\text { Axial } \\
\text { Joint } \\
\text { (mm.) }\end{array}$} & \multicolumn{2}{|c|}{ Inclination } & \multicolumn{2}{|c|}{ Mobility } & \multirow{2}{*}{$\begin{array}{l}\text { Per cent. } \\
\text { Width of } \\
\text { Original } \\
\text { Spinal } \\
\text { Canal }\end{array}$} & \\
\hline & & & & & & & $\begin{array}{c}\text { Extension } \\
\left({ }^{\circ}\right)\end{array}$ & $\begin{array}{l}\text { Flexion } \\
\left(^{\circ}\right)\end{array}$ & $\underset{(\mathrm{mm} .)}{\text { Traverse }}$ & $\begin{array}{c}\text { Angular } \\
\left(^{\circ}\right)\end{array}$ & & \\
\hline 23 & - & & & & 25.6 .57 & 8 & -4 & +8 & 6 & 12 & 75 & ब్రু \\
\hline 24 & - & & & & 8.7 .57 & 9 & -8 & +16 & 9 & 24 & 65 & $\begin{array}{l}\overline{0} \\
\tilde{N}\end{array}$ \\
\hline 25 & - & & & & 5.4 .57 & 4 & -7 & 0 & 3 & 7 & 85 & $\overrightarrow{0}$ \\
\hline 26 & - & & & & 20.5 .57 & 6 & -10 & +3 & 5 & 13 & 80 & 0 \\
\hline 27 & - & & & & 13.1 .56 & 13 & -7 & +8 & 10 & 15 & 40 & + \\
\hline 28 & - & & & & 4.1 .57 & 5 & -20 & -12 & 4 & 8 & 80 & 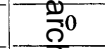 \\
\hline 29 & - & & & & 8.3 .57 & 4 & 0 & +8 & 2 & 8 & 80 & $\vec{\sim}_{0}$ \\
\hline 30 & - & & & & 20.10 .58 & 15 & -17 & +2 & 11 & 19 & 35 & $8 \stackrel{\mathscr{\mathscr { S }}}{-}$ \\
\hline 31 & 10.12 .51 & 4 & -9 & 75 & 20.5 .57 & 4 & -27 & -3 & 2 & 24 & 80 & 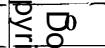 \\
\hline 32 & - & & & & 9.3 .57 & 4 & -13 & -8 & 3 & 5 & 90 & 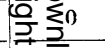 \\
\hline 33 & 18.6 .54 & 4 & -6 & 80 & 1.5 .57 & 9 & -11 & -1 & 4 & 10 & 70 & $\overline{\mathrm{Q}} 0$ \\
\hline 34 & - & & & & 9.1 .57 & $3 \cdot 5$ & -15 & -7 & 3 & 8 & 85 & $\frac{8}{80}$ \\
\hline 35 & - & & & & 15.4 .57 & 6 & -25 & -14 & 5 & 11 & 80 & $\stackrel{2}{\perp_{1}^{0}}$ \\
\hline 36 & - & & & & 12.3 .57 & 4 & -20 & -5 & 4 & 15 & 90 & $3^{0}$ \\
\hline 37 & 21.1 .57 & $2 \rightarrow 5$ & $-3 \rightarrow 0$ & 85 & 11.6 .57 & 6 & -4 & 0 & 4 & 4 & 80 & $\bar{F}^{ \pm}$ \\
\hline 38 & - & & & & 7.5.57 & 4 & -7 & 0 & 2 & 7 & 90 & 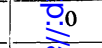 \\
\hline 39 & - & & & & 24.5 .57 & $4 \cdot 5$ & +6 & +6 & 1 & 0 & 80 & $\frac{2}{2} ?$ \\
\hline 40 & - & & & & 24.9 .56 & 5 & -10 & -2 & $4 \cdot 5$ & 8 & 85 & 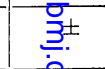 \\
\hline 41 & 20.6 .55 & 2 & -1 & 100 & 1.4 .57 & 4 & -15 & -8 & 3 & 7 & 95 & 30 \\
\hline 42 & - & & & & 29.2 .57 & 6 & -10 & 0 & 3 & 10 & 75 & $\begin{array}{l}\text { Oo } 0 \\
\text { D } \\
\text { 윽 }\end{array}$ \\
\hline 43 & 12.11 .56 & 1 & -20 & 100 & 21.7 .57 & 13 & -21 & +12 & 12 & 33 & 35 & Nم \\
\hline 44 & - & & & & 30.1 .57 & 4 & -19 & -7 & 3 & 12 & 85 & No \\
\hline 45 & 12.4 .50 & 4 & +5 & 80 & 20.6 .55 & 8 & +12 & N.A. & N.A. & N.A. & 50 & $\begin{array}{l}\tilde{\omega} \\
\mathrm{\omega} \\
0\end{array}$ \\
\hline 46 & - & & & & 7.2 .57 & $4 \cdot 5$ & -10 & -3 & 4 & 7 & 70 & 产 \\
\hline 47 & - & & & & 2.8 .56 & 18 & -2 & +4 & 10 & 6 & 35 & $\begin{array}{l}8 \\
+98 \\
7\end{array}$ \\
\hline 48 & - & & & & 21.2 .57 & $8 \cdot 5$ & 0 & N.A. & N.A. & N.A. & 55 & +0 \\
\hline
\end{tabular}


of the third thoracic segment. Position sense was impaired in the fingers of both hands. $X$ rays (Fig. 8, overleaf; Table VIII) revealed gross atlanto-axial dislocation.

Skull traction by means of Crutchfield callipers immediately relieved the pain in the neck and head and resulted in satisfactory reduction of the displacement. An occipito-cervical fusion was then performed. After this she was depressed, apathetic, hallucinated, and

\section{TATIENTS WITH RHEUMATOID ARTHRITIS}

\begin{tabular}{|c|c|c|c|c|c|c|c|c|}
\hline \multirow{3}{*}{ Treatment } & \multirow{3}{*}{ Clinical Result } & \multicolumn{7}{|c|}{ Last Film } \\
\hline & & \multirow{2}{*}{ Date } & \multirow{2}{*}{$\begin{array}{l}\text { Depth } \\
\text { Ant. } \\
\text { Atlanto- } \\
\text { Axial } \\
\text { Joint } \\
\text { (mm.) }\end{array}$} & \multicolumn{2}{|c|}{ Inclination } & \multicolumn{2}{|c|}{ Mobility } & \multirow{2}{*}{$\begin{array}{l}\text { Per cent. } \\
\text { Width of } \\
\text { Original } \\
\text { Spinal } \\
\text { Canal }\end{array}$} \\
\hline & & & & $\underset{\left({ }^{\circ}\right)}{\text { Exten }}$ & $\underset{\left({ }^{\circ}\right)}{\text { Flexion }}$ & $\begin{array}{c}\text { Traverse } \\
\text { (mm.) }\end{array}$ & $\underset{\left({ }^{\circ}\right)}{\text { Angular }}$ & \\
\hline None & $\begin{array}{l}\text { Continued symptom-free (Decem- } \\
\text { ber, 1957) }\end{array}$ & 30.12 .57 & 8 & -5 & +10 & 6 & 15 & 70 \\
\hline Collar & $\begin{array}{l}\text { Continuing symptom-free (Novem- } \\
\text { ber, 1959) }\end{array}$ & 5.11 .57 & 9 & -4 & +15 & 9 & 19 & 65 \\
\hline Collar intermittently & $\begin{array}{l}\text { Relief of pain and neurological } \\
\text { symptoms and signs }\end{array}$ & 4.3.59 & 5 & -10 & -2 & $3 \cdot 5$ & 8 & 85 \\
\hline Collar & Pain incompletely controlled & 3.2 .59 & 7 & -12 & +5 & $5 \cdot 5$ & 17 & 80 \\
\hline Traction. Collar & $\begin{array}{l}\text { Temporary improvement on trac- } \\
\text { tion. Deterioration in collar. } \\
\text { Died October, } 1956\end{array}$ & - & & & & & & \\
\hline Collar & Complete relief of pain & 17.7.59 & 2 & -21 & -12 & 2 & 9 & 90 \\
\hline Collar & Complete relief of pain & 15.7.57 & 4 & 0 & +3 & 1 & 3 & 85 \\
\hline Traction. Unsuccessful fusion & $\begin{array}{l}\text { Death from septicaemia and mul- } \\
\text { tiple pyarthroses, September, } 1959\end{array}$ & 11.9 .59 & 13 & -10 & +3 & 2 & 13 & 35 \\
\hline None & No symptoms & 26.8 .57 & 5 & -25 & -3 & 2 & 22 & 75 \\
\hline None & Patient defaulted & & & & & & & \\
\hline Collar when sitting up & No symptoms & & & & & & & \\
\hline None & No symptoms & 13.7 .57 & 4 & -16 & -8 & 4 & 8 & 85 \\
\hline None & No symptoms & 31.7 .57 & 6 & -23 & -16 & 4 & 7 & 75 \\
\hline None & No symptoms & 25.7.57 & 5 & -21 & -6 & 5 & 15 & 85 \\
\hline Collar & Good relief of pain & 25.5 .59 & 6 & -2 & +3 & 2 & 5 & 75 \\
\hline None & Minor neck stiffness only & & & & & & & \\
\hline Collar & $\begin{array}{l}\text { Died at home of a "seizure" } 3 \text { days } \\
\text { after application }\end{array}$ & - & & & & & & \\
\hline $\begin{array}{l}\text { Equivocal plantar responses. } \\
\text { Collar. Steroids }\end{array}$ & Partial pain relief & - & & & & & & \\
\hline None & $\begin{array}{l}\text { Continuing symptom-free (January, } \\
1960 \text { ) }\end{array}$ & - & & & & & & \\
\hline None & $\begin{array}{l}\text { Also had staphylococcal septi- } \\
\text { caemia with metastatic infection } \\
\text { of 7th cervical spinous process } \\
\text { responding to antibiotics }\end{array}$ & 8.7 .57 & 8 & -16 & +2 & 6 & 18 & 65 \\
\hline $\begin{array}{l}\text { Collar in vehicles, etc., when risk } \\
\text { of violent neck flexion }\end{array}$ & No symptoms & 6.5 .59 & $12 \cdot 5$ & -21 & +10 & $11 \cdot 5$ & 31 & 40 \\
\hline Collar for a few weeks & No symptoms & 25.2 .59 & $3 \cdot 5$ & -24 & -5 & $3 \cdot 5$ & 19 & 90 \\
\hline Traction. Fusion & $\begin{array}{l}\text { Neurological improvement. Pain } \\
\text { relieved }\end{array}$ & 23.2.59 & 6 & +2 & +2 & 0 & 0 & 65 \\
\hline Collar & $\begin{array}{l}\text { Good pain relief (maintained } \\
\text { April, 1957) }\end{array}$ & & & & & & & \\
\hline Traction. Fusion & Major neurological recovery & 19.11.57 & $3 \cdot 5$ & -8 & -8 & $\mathbf{0}$ & 0 & 85 \\
\hline Traction. Fusion & $\begin{array}{l}\text { Almost complete neurological } \\
\text { recovery }\end{array}$ & 2.10 .58 & $8 \cdot 5$ & +5 & +5 & 0 & 0 & 55 \\
\hline
\end{tabular}




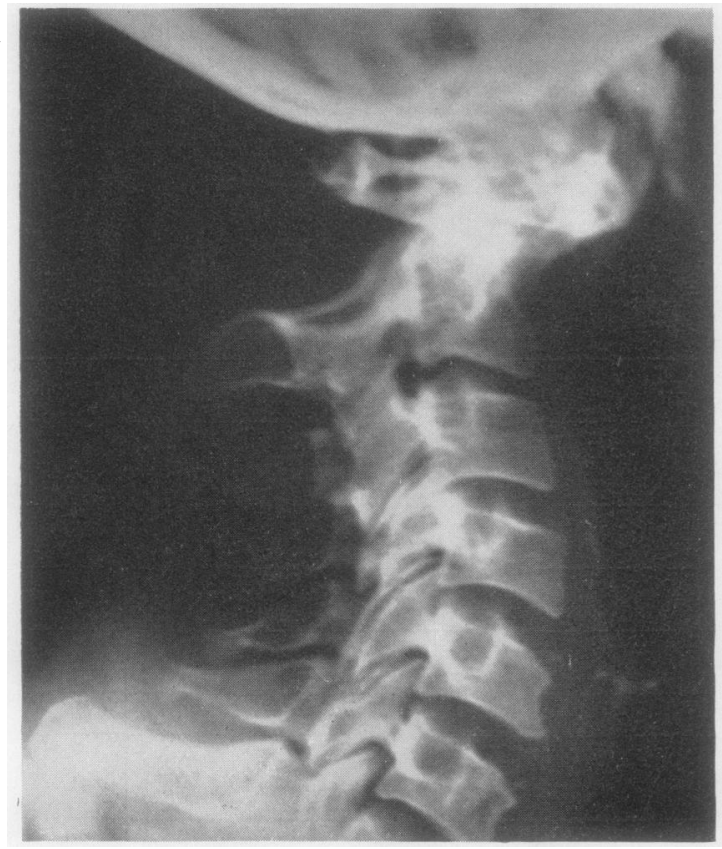

Fig. 8.-Case 47; radiograph showing severe forward dislocation of the atlas on the axis.

disorientated as to time and place for some 10 weeks, but after her return to a normal mental state her progress was satisfactory. As she became more mobile the left knee from which deep pain sensibility was absent became more unstable, but she returned to a completely independent active life walking without sticks. When last seen 3 years after the operation she was very well, but still had a left lower quadrantic loss of pain and temperature sensibility up to the level of the twelfth dorsal segment and minimal pyramidal signs.

Comment.-This patient had recognized the alteration in quality of her pain which had resulted from the disturbance of pain pathways in the spinal cord in addition to the other sensory disturbances. She was at serious risk at the time of the herniorrhaphy when she clearly had a severe unstable atlanto-axial dislocation.

\section{Presentation as a Chance Radiological Finding.-} In thirteen patients with rheumatoid arthritis the displacement was not suspected until radiographs of the cervical spine were examined. In none of them could a definite diagnosis have been made clinically, and detailed inquiry after the displacement had been diagnosed radiologically failed to elicit even a history of sub-occipital pain in six of them. This contrasts with the findings in the spondylitic patients, all of whom had symptoms of the displacement at some stage.
Case 33. Rheumatoid Arthritis.-A 60-year-old housewife first attended in 1949 with 6 months' history of painful swelling of the right knee. In 1950 the hands and feet became involved and in 1953 she developed severe rheumatoid changes in almost all the limb joints with mild restriction of spinal movement and some pain in the neck. In 1954 she was admitted to hospital and after rest in bed, intensive aspirin, and gold therapy, she had an excellent remission though with severe residual changes in the joints.

When the radiographs of hospital in-patients were reviewed for another purpose, an atlanto-axial subluxation was noted on a film of this patient taken in 1954 (Table VIII). On re-examination in 1957, apart from minor recrudescences, the remission of the arthritis had been maintained and she was leading a bed-chair existence with little pain. Her head was carried slightly forward but the deformity was hardly appreciable; neck flexion was full but movements in other directions particularly extension, although limited, were virtually painless. She could not recall ever having had any sub-occipital pain and there was no evidence of any neurological disturbance. Further radiographs indicated that the displacement had probably increased over the 3 intervening years (Table VIII). She was fitted with a supporting collar for use when sitting out of bed.

\section{Duration of Symptoms of the Displacement before Diagnosis}

An attempt was made by detailed questioning to determine when the patients had first developees symptoms indicating the atlanto-axial displacement: This was usually found to be easier in the spondylitic patients. In them the first symptoms of the displacement had occurred from 2 months to 5 years before it was diagnosed (Table V). In Case 7, where the displacement was fixed and was causing no symptoms at the time of diagnosis, these had been present for 2 months 3 years previously. In the remainder, symptoms of the displacement had been present constantly or intermittently from their appearance to the time of diagnosis. With three possible exceptions (Cases 1, 6, and 16 (Table V)), it appeared from the patients' histories that the disease process had been active at the time when the displacement had occurred.

In the seventeen rheumatoid patients in whom the duration of symptoms of the displacement could be ascertained with reasonable assurance, these had been present for from 2 weeks to 13 years, nine patients having had them for more than 1 year and four for 5 years or more. Since six of the thirteen patients in whom the displacement was first noted on radiographs had had no symptoms to indicate its presence, the displacement could also have been present for varying periods before the symptoms developed in the other patients. 


\section{Radiological Features}

The radiological features of the patients with ankylosing spondylitis are indicated in Table VII, and of those with rheumatoid arthritis in Table VIII. The measurements recorded in these Tables which are illustrated in Fig. 9 were derived as follows:

(1) The depth of the anterior atlanto-axial joint was taken as the distance between the middle of the posterior surface of the anterior arch of the atlas and the anterior surface of the odontoid process. Measurements were made using dividers on the film taken in flexion when available.

(2) The inclination of the atlas to the axis was taken as the angle between the line joining the inferior borders of the anterior and posterior arches of the atlas and that joining the inferior border of the body of the axis and of its spinous process. A negative angle of inclination was recorded when the lines converged posteriorly and a positive angle when they converged anteriorly.

(3) The "traverse" of the atlas on the axis represented the increase in depth of the anterior atlanto-axial joint in flexion, and the angular mobility was derived from the algebraic difference between the angle of inclination of the atlas to the axis in flexion and that in extension.

(4) The antero-posterior diameter of the spinal canal on the film taken in flexion was measured as the shortest distance between the anterior surface of the posterior arch of the atlas and the posterior surface of the odontoid process. This was expressed as a percentage of that of the estimated original spinal canal of that individual to the nearest 5 per cent. The original size of the spinal canal was estimated by subtracting the antero-posterior diameter of the odontoid process plus an arbitrary $1 \mathrm{~mm}$. for the original depth of the atlanto-axial joint from the distance between the anterior surface of the posterior arch and the posterior surface of the anterior arch of the atlas. Using the symbols for these measurements as in Fig. 9, the calculation is represented by the formula:

$$
\frac{c}{D-(B+1)} \times 100
$$

As can be seen from Tables VII and VIII, the main determinant of the degree of narrowing of the spinal canal was the increase in depth of the anterior atlanto-axial joint, but extreme degrees of inclination of the atlas, either forwards or backwards, further increased the narrowing of the canal. Thus, in Cases 11 and 12 (Table VII), the depth of the anterior atlanto-axial joint was $10 \mathrm{~mm}$. in each case but extreme forward tilting of the atlas in Case 12 had resulted in narrowing of the canal to 30 per cent. of the original compared with 70 per cent.

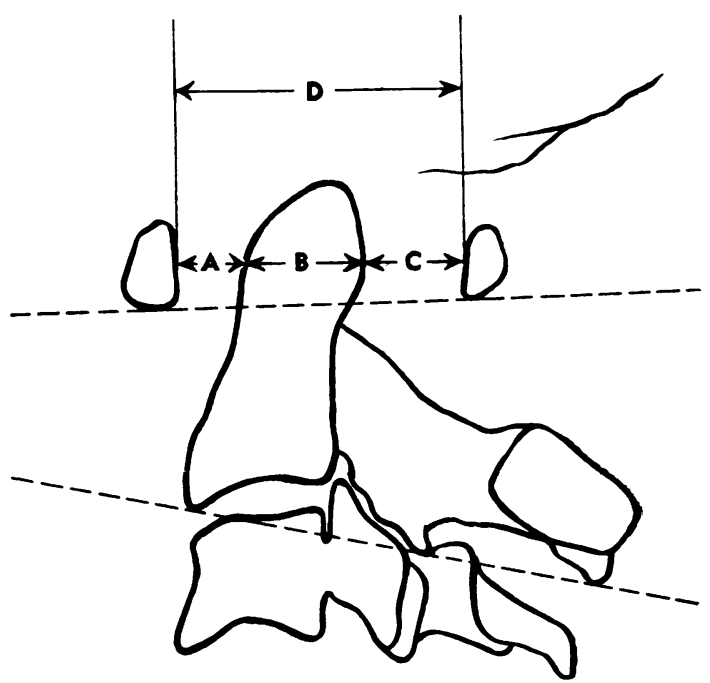

Fig. 9.-Diagram to illustrate measurements recorded in Tables VII and VIII.

in Case 11 in whom the forward tilting was much less. In Case 18, hyperextension at the atlantoaxial level slightly aggravated the narrowing of the canal consequent on the forward displacement of the atlas.

Two further changes were observed in the rheumatoid but not in these spondylitic patients. In a few, destructive changes in the lateral articular processes of the atlas and axis had resulted in a downward displacement of the atlas relative to the odontoid process which commonly broadens out inferiorly so that this tended to increase the narrowing of the canal. More often, there was erosion of the odontoid process, and when this affected the posterior and apical aspects this tended to decrease the narrowing of the spinal canal resulting from a given degree of anterior displacement of the atlas.

As might be expected, the most serious neurological lesions were observed in both conditions in patients with the greatest narrowing of the spinal canal. Thus, three of the five spondylitics and four of the five rheumatoid patients in whom the spinal canal was known to be narrowed to 50 per cent. of the normal or less had neurological changes of some severity. In one of the two exceptions among those with spondylitis, Case 7, the displacement was fixed radiologically on films taken $4 \frac{1}{2}$ months after diagnosis. In the other, Case 3, films in flexion and extension were not taken, but clinically the spine was rigid. The rheumatoid patient was a 31-year-old female (Case 43) who had an exceptionally mobile displacement with narrowing of the 
canal to 35 per cent. of normal in flexion but who had no symptoms of the displacement and no neurological abnormalities.

Among the remaining spondylitic patients, Case 9, in whom the canal was narrowed to 75 per cent., and Case 10, with narrowing to 80 per cent., had moderately severe and mild cord damage respectively, and in Case 21 in which the evidence of mild cord damage was not conclusive the canal was narrowed to 70 per cent. of normal. In Case 6, which showed a rotary dislocation with moderate cord damage, the degree of narrowing of the canal could not be measured, and in Case 22, with evidence of fairly severe cord damage, the films taken before operation were not available.

In the rheumatoid patients the spinal canal in Case 48 , in which there was a very severe cord lesion, was narrowed to 55 per cent. of normal in the conventional lateral view, but films in flexion were not taken. In Case 25, where the canal was 85 per cent. of normal, there were mild neurological changes, and in Case 24 and Cases 26, 37, and 40 there was equivocal evidence of cord damage with canals of 65 per cent. and of 80 to 85 per cent. of normal respectively.

In five of the thirteen patients with neurological changes (Cases 5, 6, 12, 22, and 48, including some with the most severe neurological lesions), films were not taken in flexion and extension so that the degree of abnormal mobility present could not be measured and the importance of this as a factor in the production of cord damage could not be assessed from this study. Although the findings in Case 43 provide a striking exception, we suspect that as a rule severe abnormal mobility may be an important contributory cause of cord damage.

\section{Progress of Patients in Relation to Treatment}

\section{(1) Before Diagnosis}

The radiological findings in the thirteen spondylitic and six rheumatoid patients in whom radiographs of the cervical spine taken at some time before the diagnosis of the displacement were available are indicated in Tables VII and VIII respectively. The findings in the earliest available films were recorded and with the exception of Case 37, who had had films in flexion and extension, the remainder had only conventional single lateral films.

In three of the spondylitic patients (Cases 2, 11, and 12; Table VII), a forward subluxation of the atlas was visible on the earlier film, and in each case the displacement was more marked on the films taken at the time of diagnosis. Since, however, the presence or full degree of displacement may be apparent only on films taken with the neck fully flexed (Fig. 1), it cannot be concluded that the displacements had increased in the interval, or that they were necessarily absent in those in whom the appearances on the earlier conventional single lateral films were normal. In Case 16 radiographs in flexion and extension taken 2 years before diagnosis, at which time the patient had symptoms strongly suggesting a mobile atlanto-axial displacement, had revealed no evidence of this. The symptoms subsided spontaneously but recurred in more severe form in November, 1958, 3 months before the films revealing the displacement were taken.

An atlanto-axial displacement was visible on the earlier films of four of the six rheumatoid patients in whom these were available, Cases $31,33,37$, and 45. Only in Case 31 had the displacement not apparently progressed at the time of diagnosis.

\section{(2) After Diagnosis}

(a) Without Treatment.-Four of the spondylitic patients were given no specific treatment for the displacement (Cases 1, 4, 8, and 20; Table VII). Case 4 was lost to follow up. In Case 1 the pain was relieved by aspirin and the displacement had not appreciably altered on radiographs taken 7 months later. In Case 8 intermittent episodes of pain from the displacement continued over $3 \frac{1}{2}$ years, but during this interval the displacement became reduced and the atlanto-axial mobility greatly diminished. In Case 20 the diagnosis was made only at autopsy; during the 9 months before death the patient had developed a progressive and ultimately complete tetraplegia and his death from debility and secondary infection was directly attributable to the atlanto-axial dislocation.

In seven of the nine rheumatoid patients given no specific treatment (Cases 23, 31, 32, 34, 35, 36, and 41: Table VIII), the displacement was producing no symptoms, and in Case 38 it was causing only minor pain. In Case 42 the wearing of a collar was made impossible by an infection of the seventh cervical spinous process as one of numerous sites of metastatic infection from staphylococcal septicaemia: the neck symptoms subsided with control of the infection. None of them had neurological changes. In each of the six patients who had further radiographs 3 to 6 months after diagnosis, there had apparently been further slight narrowing of the canal but with the exception of Case 42 the individual differences were probably within the error of measurement, and in Case 42 restriction of 
neck movement due to pain from the bone infection may have prevented demonstration of the full range of abnormal mobility on the original films. Those initially without symptoms continued so throughout periods of observation of up to $2 \frac{3}{4}$ years.

(b) Treatment by External Support.-To achieve virtually complete immobilization of the upper cervical spine by external means in an ambulant patient, fixation to the skull either by incorporation of skull callipers in a Minerva plaster or by a device such as the "halo brace" (Perry and Nickel, 1959) is required. The conventional Minerva plaster does not immobilize the upper cervical spine (Fig. 10) and may not maintain reduction of an unstable atlanto-axial displacement.

In Case 27 there was an almost complete tetraplegia at the time when severe atlanto-axial dislocation was diagnosed. Good reduction of the displacement was achieved by skull traction, the antero-posterior diameter of the spinal canal returning to 95 per cent. of normal. The reduction was maintained in the first of two Minerva plasters which held the cervical spine in extreme extension, but radiographs in a second plaster applied 3 weeks later with the head in a more normal position revealed that the displacement had increased, the

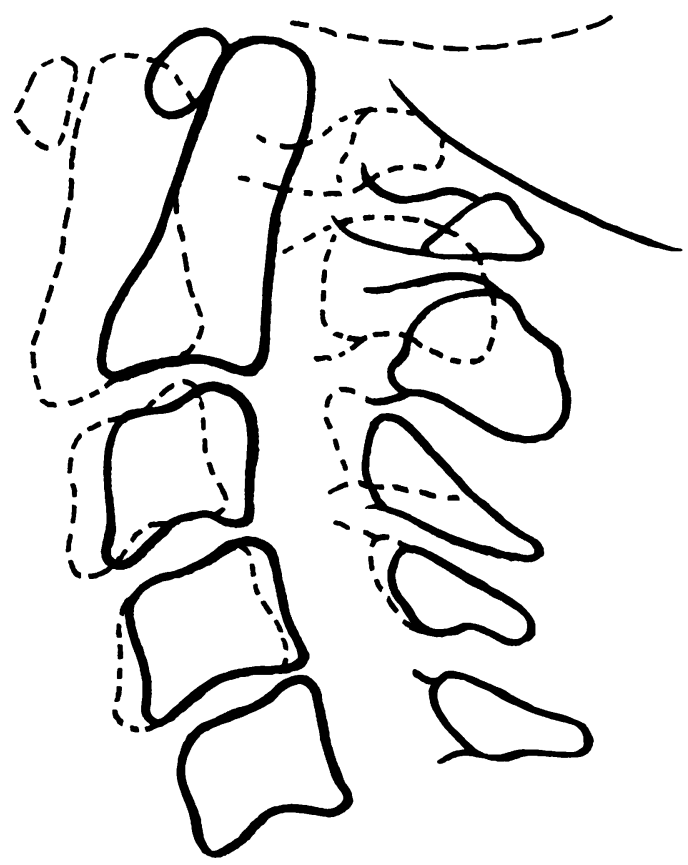

Fig. 10.-Tracings of radiographs of the cervical spine of a patient in a Minerva plaster, showing range of movement permitted. canal now being only 75 per cent. of the normal diameter (Fig. 11a, overleaf). On films taken 4 weeks later in the same plaster the atlas had slipped further forwards so that the canal was now narrowed to 50 per cent. of normal (Fig. $11 b$, overleaf). From the time of institution of traction there had been steady and substantial neurological improvement and this continued up to the application of the second plaster. Thereafter, the patients' neurological status and functional capacity steadily deteriorated. After 3 months, the second plaster was replaced by a block leather collar, but the deterioration continued and after one month in the collar he was allowed to return home at his own request. He died 4 months later but we have been unable to obtain any further information about him.

Any form of supporting collar which allows the patient to speak and chew must also permit some upper cervical movement. Patients were therefore provided with supporting collars with the objects of restricting cervical movement, relieving pain, and affording some mechanical protection from violent head movements, notably flexion, and for the not unimportant reason that the collars also served to remind those looking after them of the presence of the lesion. Most of the patients were given a simple padded cardboard collar, but in a few instances more durable collars made of plastic material padded with foam rubber or of moulded block leather were provided and, as described below, one spondylitic patient was treated by serial plaster collars. The collars were well tolerated by the spondylitic patients, but greater care was necessary in those with severe rheumatoid arthritis to prevent pressure necrosis of the skin.

Four spondylitic patients were given cardboard or plastic collars as the only local treatment (Cases 2, 7, 16, and 18: Table VII). In Case 7, a stable displacement causing no symptoms was treated by a collar worn only while the patient was in hospital undergoing vigorous physical treatment. In the others pain from the displacement was completely relieved. In Case 2 partial and in Case 16 almost complete reduction of displacement occurred over periods of 20 and 15 months respectively. In Case 18 the displacement increased, but the abnormal mobility greatly diminished during 27 months of observation. Case 15 was at first treated with a cardboard collar and later with a plastic collar by day and cardboard one at night. Initially, his pain was satisfactorily relieved but it then recurred and after 4 months was more severe than at the outset. By this time there had been a very 
slight increase in the forward displacement of the atlas, which was tilted forwards on the axis and almost fixed in the position of maximum deformity with further slight narrowing of the canal to 65 per cent. of normal. Reduction of the displacement by skull traction followed by occipito-cervical fusion completely relieved his pain and restored the canal to 90 per cent. of the normal diameter.

Case 14, an elderly Chinese male, who had a mild atlanto-axial displacement associated with a very severe lumbo-dorsal flexion deformity, was treated by periods of recumbency and serial plaster collars with considerable but only temporary decrease in the deformity, but little if any effect on the displacement. One year after treatment there had been a minimal increase in the forward displacement of the atlas, but the angular mobility had diminished. He was suffering little pain and declined further treatment.

Of the rheumatoid patients, twelve were treated by supporting collars. Case 39 (Table VIII), who had a relatively mild and almost fixed displacement, died at home 10 hours after a "seizure" which occurred 3 days after the displacement had been diagnosed and she had been fitted with a padded cardboard collar; no further details could be obtained. The remainder wore collars continuously or intermittently for periods ranging from a few

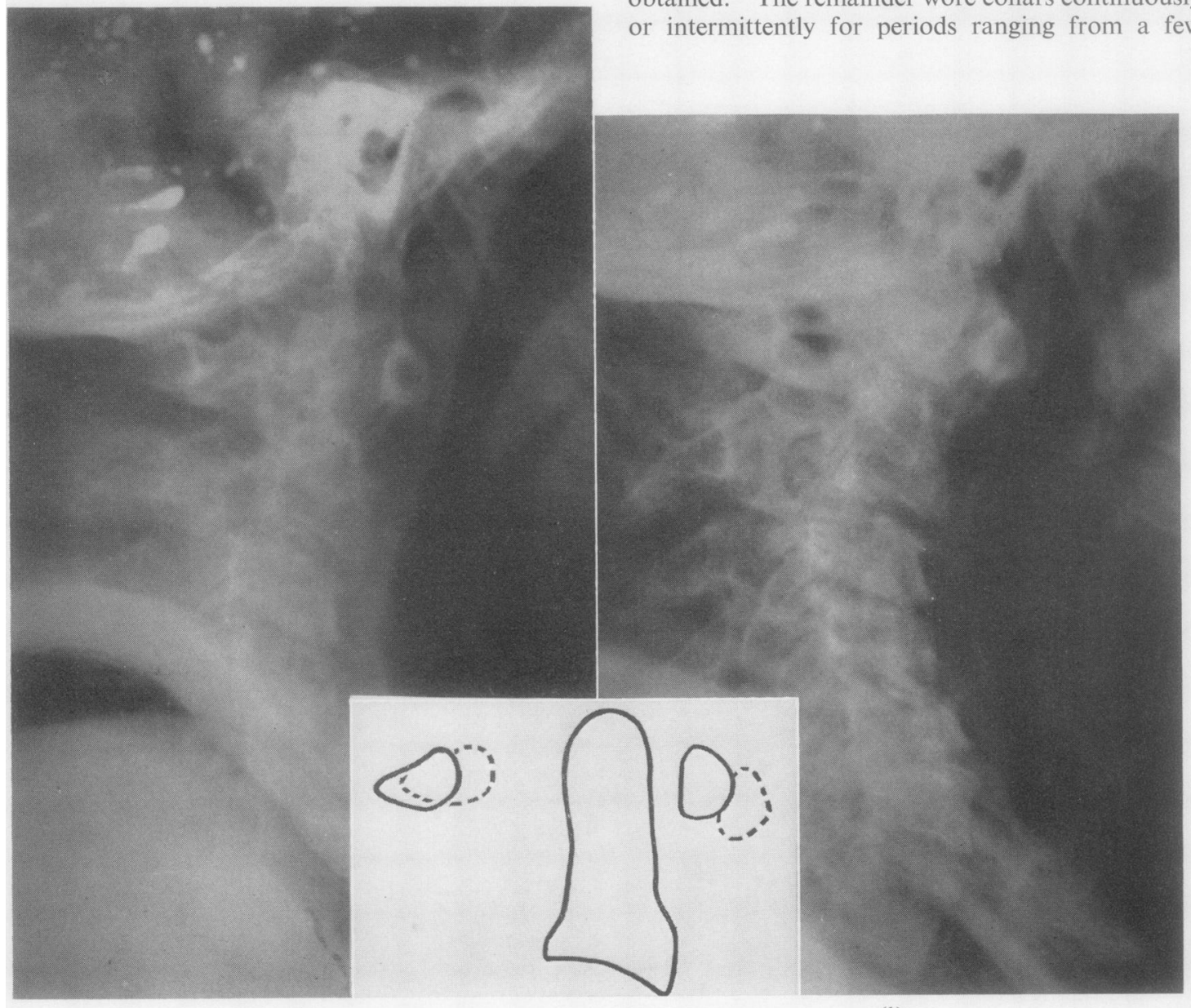

(b)

Fig. 11.-Case 27; radiographs in the second Minerva plaster.

(a) shortly after application; (b) one month later.

There has been a substantial increase in the forward displacement of the atlas in the interval. 
weeks to $2 \frac{1}{2}$ years (Case 28). In four of them (Cases 24, 33, 43, and 44) the displacement was causing no symptoms though Case 24 had equivocal plantar responses. Each of the three patients followed up for from 4 to 25 months, continued symptom free and the displacements did not alter materially. The seven remaining rheumatoid patients treated by collars only all had pain from the displacement. In Cases 25, 28, and 29, pain was completely relieved. In Case 25 evidence of mild cord damage also disappeared during 23 months' observation, although radiologically there was little alteration in the displacement. In Case 28 the displacement became reduced and the abnormal mobility subsided over $2 \frac{1}{2}$ years, and in Case 29 also the abnormal mobility decreased over a period of 4 months. Cases 26, 37, and 46 derived good but not complete relief of pain. In Case 26 the displacement increased slightly over 20 months. In Case 37 the forward displacement remained constant but the antero-posterior traverse of the atlas on the axis decreased over 2 years and as a result reduction of the displacement became less complete in extension. Both Case 26 and Case 37 had equivocal evidence of cord damage and there was no evidence of deterioration in this respect. Case 46 was only observed for 2 months and had no further radiographs. Case 40 was averse to wearing a collar from the start and relief of pain in her case was less satisfactory than in the other patients; when steroid therapy was begun one month later there was considerable psychological and functional improvement, and she complained much less of pain from both the displacement and the arthritis. Her plantar responses remained equivocal.

(c) Treatment by Occipito-Cervical Fusion.-Two of the spondylitic patients (Cases 19 and 22), whose case histories are outlined in the Appendix had undergone occipito-cervical fusion elsewhere some years before being seen by us. Pain had been a prominent symptom in both cases and in Case 22 there was, in addition, evidence of severe cord damage which largely regressed after operation.

Nine other spondylitic and four rheumatoid patients underwent occipito-cervical fusion. Skull traction was maintained pre-operatively until radiographs revealed that no further reduction was occurring, and it was continued during the operation, which consisted of the insertion of an iliac crest autogenous bone graft extending from the occiput to the upper cervical laminae and spinous processes. Post-operatively, the traction was continued in some cases until the graft was united.
In others it was replaced by a Minerva plaster incorporating the skull callipers, and in one man, Case 15 , by a "halo brace", until union had occurred. The patients carried out supervised limb and breathing exercises throughout the programme.

Pain from the displacement was present in each of the nine remaining spondylitic patients undergoing fusion and was the major indication for operation in four of them (Cases 10,11, 17, and 21: Table VII). The operation completely relieved the pain in all cases. Cord damage was the main indication for operation in three patients (Cases 5, 9, and 12); in Cases 5 and 12 there was almost complete regression of the neurological changes after operation, and in Case 9 there was moderate improvement. Case 10 had evidence of mild cord damage and Case 21 equivocal evidence of cord damage which disappeared after operation.

As stated previously, the operation in Case 3 was mainly done because of severe deformity and in Case 15 because of the failure of supporting collars to control pain and prevent progression of the displacement.

In the four rheumatoid patients (Cases 30, 45, 47 , and 48), the indication for operation was damage to the spinal cord. The post-operative course in Case 30 was complicated by infection of the donor site at the iliac crest and breakdown of the occipital incision, the bone graft failing to unite. During the first few post-operative weeks there was a temporary deterioration in his neurological status and as this was regressing the picture became complicated by the development of a peripheral neuropathy and of other features strongly suggesting disseminated vasculitis. He developed septicaemia and died 10 months after operation. In the others the results were very satisfactory and there was virtually complete neurological recovery in Case $\mathbf{4 5}$ and substantial improvement in Cases 47 and 48.

(d) Treatment by Other Methods.-Two spondylitic patients, Cases 6 and 13, had rotary subluxation of the atlas on the axis.

In Case 6, the more severe, a fixed deformity with the chin fully rotated to the right, was treated by traction in extension with an additional force applied to the right limb of the skull calliper to correct the rotation. During the 16 days of traction necessary to reduce the displacement there was a transient increase in the previously mild pyramidal signs. After reduction he was treated in two Minerva plasters, the first incorporating the skull callipers, and finally in plastic collar. On a film taken one year after discharge from hospital (Table VII), there was minimal forward displacement of the atlas with 
lateral tilting. When examined 2 years after discharge, he had no cervical symptoms and there were only minimal residual pyramidal signs. Clinically and radiographically there was no movement in the upper cervical region and the atlanto-axial relationships were unchanged from those indicated in Table VII.

In Case 13 there was only a minimal rotary displacement, but this was causing intolerable, predominantly unilateral pain. This was immediately relieved by skull traction which was followed by plaster and then a cardboard collar for a few weeks. 34 months after treatment there had been no recurrence and the atlanto-axial relationships were radiographically normal (Table VII).

\section{Discussion}

Atlanto-axial displacement is a relatively common event in rheumatoid arthritis, the minimal prevalence in those members of the general population with any evidence of the disease being approximately one in thirty, in those with clinical evidence one in fifteen, and in those with disease sufficiently severe for them to be admitted to hospital almost one in five. In most cases the displacement is mild and, though few patients suffer serious harm from the lesion, it is important that it should be diagnosed, since an unstable displacement may progress and produce grave and occasionally fatal neurological complications. The frequency with which this lesion occurs in ankylosing spondylitis could not be determined from this study, but it is certainly less than in rheumatoid arthritis. It is, however, possible that it now occurs more frequently than formerly in ankylosing spondylitis as a result of the effective pain relief afforded to many spondylitic patients by $x$-ray therapy and other more recently developed agents, and because of the emphasis now laid on the importance of active movement in retaining mobility of the spine and limbs in this condition.

Clinical diagnosis of this complication is usually easier in ankylosing spondylitis than in rheumatoid arthritis where it may develop without any characteristic symptoms or striking physical signs. Active arthritis of the atlanto-axial joints usually results in upper cervical pain increased by sudden head movements and, when severe, the pain may radiate to the occipital, temporal, and frontal regions, but severe pain in these situations, particularly lancinating pains when the spine is jarred, as in riding in vehicles, should immediately arouse suspicion of abnormal atlanto-axial mobility. A complaint of the head "falling forwards" and of difficulty in restoring it to the normal position voluntarily may be present with mild displacements which have produced no appreciable flattening of the occipitocervical curve; difficulty in shaving under the chin may be an early symptom. Failure to appreciate the significance of such symptoms in some of the spondylitic patients studied had resulted in their having been given unwarranted and unsuccessful $x$-ray therapy.

The diagnosis ultimately rests on the radiographic demonstration of the abnormal relationship of the atlas to the axis. While in many instances there is a rotary component in the displacement, one facet of the atlas slipping further forwards than the other, in the great majority the main displacement is of the atlas forwards on the axis and the diagnostic radiological feature is an increase in the distance between the anterior arch of the atlas and the odontoid process. From the studies of the general population it would appear that after age 45, a gap of more than $3 \mathrm{~mm}$. on a conventional single lateral radiograph is probably abnormal and highly likely to be associated with other evidence of an inflammatory polyarthritis, but that a distance of $4 \mathrm{~mm}$. may be normal in younger subjects. Studies of hospital patients, however, suggest that in certain individuals a distance of $3 \mathrm{~mm}$. may be abnormal and that even so small a displacement may be responsible for very severe pain. For certainty of diagnosis it is essential that a radiograph should be taken with the neck fully flexed, since one taken in the neutral position may fail to reveal a mobile displacement. A film with the neck extended is also desirable in order that the degree of abnormal mobility at the atlanto-axial level and also the possible presence of abnormal mobility at other levels in the cervical spine may be ascertained.

The major hazard of the lesion is damage to the medulla and spinal cord. The early indications of this can easily be missed or attributed to "functional overlay", particularly in patients with severe anatomical changes in the limbs and spine in whom neurological examination is difficult. Several patients in this series had had early symptoms of cord damage, in some cases for many months, the significance of which was only appreciated when more obvious neurological changes developed. The occurrence of cord damage is probably related not only to the extent of the displacement but also to the degree of abnormal mobility present. In view of the relatively much greater prevalence of atlantoaxial displacement in rheumatoid arthritis than in ankylosing spondylitis, it would appear that neurological complications of the lesion are more likely to occur in the latter condition. It is possible that 
the erosion of the odontoid process observed more frequently in rheumatoid patients, by increasing the space available for the cord, may be one factor in this, but other important factors may be the greater ability of the cord to adapt itself to deformity of the spinal canal through the relaxing effect on the cord of the narrowing of multiple disks, a change commonly present in rheumatoid arthritis, and the tethering effect of the rigidity of the lower cervical region usually present in spondylitic patients.

Observation of the progress of some spondylitic patients would indicate that it is possible for the atlas to become stable in the displaced position, that a minor mobile displacement may become reduced, and that the abnormal mobility may subside without treatment. Spontaneous stabilization of a displacement was not observed in the rheumatoid patients in this series, but may occur in the deformed position if the inferior atlantoaxial joints become ankylosed (Ball, 1960). How often this occurs will be determined only by the long-term observation of larger numbers of patients. Meanwhile, early diagnosis of the displacement appears highly desirable not only that the patient may receive appropriate treatment to relieve any associated symptoms, but also that he may be protected from the risk of damage to the cord from minor trauma, particularly during physical treatment or anaesthesia. In any patient suspected of having such a displacement, or in any patient with severe rheumatoid arthritis undergoing general anaesthesia, radiographs taken with the neck gently flexed and extended are advisable. Those with minor degrees of displacement appear to be adequately protected by a supporting collar and this usually relieves any associated pain, but if there is intolerable pain unrelieved by this means, if the displacement progresses in spite of such support, or if neurological complications are present, reduction of the displacement and occipito-cervical fusion are indicated. This will relieve the associated pain and may be followed by remarkable regression of severe neurological changes.

\section{Summary}

From a study of radiographs of the cervical spine of samples of the general population it was concluded that after age 45 a separation of more than $3 \mathrm{~mm}$. of the odontoid process from the anterior arch of the atlas on a conventional lateral film is usually abnormal and highly likely to be associated with rheumatoid arthritis, though in younger subjects a gap of $4 \mathrm{~mm}$. may be normal. The clinical studies suggest that occasionally a gap of even $3 \mathrm{~mm}$. may be abnormal.

The prevalence of atlanto-axial displacement, so defined, in those members of the general population with any eyidence of rheumatoid arthritis was 32 per thousand, in those with clinical evidence of the disease 64 per thousand, and in those with rheumatoid arthritis admitted to hospital 189 per thousand. The lesion was observed much less frequently in ankylosing spondylitis, but a definite prevalence rate could not be established from this study.

The clinical and radiographic features were studied of 22 patients with ankylosing spondylitis and 26 with rheumatoid arthritis who had developed spontaneous displacements of the atlas on the axis; it was found that in the spondylitic patients there was invariably some clinical evidence of the displacement but that this was absent in a substantial proportion of those with rheumatoid arthritis, the diagnosis in such cases being made only from routine radiographs taken with the neck extended and flexed; a mobile displacement was sometimes not apparent on a single lateral radiograph taken in the neutral position.

The characteristic clinical features of the displacement were:

(1) Pain in the upper part of the neck radiating to the occipital and sometimes to the temporal and frontal regions, greatly aggravated by jarring movements.

(2) Difficulty in getting the head back after looking downwards, often accompanied by difficulty in shaving under the shin and a sensation of "falling forwards" of the head.

(3) Flattening of the occipito-cervical curve, often accompanied by some degree of torticollis.

In a few instances the presenting manifestations of the displacement were signs of damage to the spinal cord; in some of these the diagnosis presented great difficulty and in the first patient presenting in this way it was made only at autopsy. In all, six of the rheumatoid and seven of the spondylitic patients had evidence of cord damage. The severity of the neurological changes was roughly correlated with the degree of narrowing of the spinal canal, but some patients escaped damage to the cord in spite of a gross degree of displacement.

Spontaneous stabilization of the displacement may occur without treatment, but it is not known how often this occurs and in both conditions displacements were observed to progress in some untreated patients. The majority were therefore treated by supporting collars, usually with satisfactory relief 
of pain and sometimes with reduction both of the degree of displacement and of the abnormal mobility. In one patient with rheumatoid arthritis, severe neurological changes had regressed following skull traction but there was progressive neurological deterioration after the application of a Minerva plaster followed by a block leather collar. Increase in the displacement during the period in plaster was observed.

Four of the rheumatoid patients were treated by occipito-cervical fusion, the indication for operation in each case being the presence of neurological signs. This was also the main indication in four of the eleven spondylitics who were treated by operation, the main indications in the others being pain in five, severe deformity in one, and progression of the displacement despite a collar in one. With the exception of one of the rheumatoid patients in whom fusion was unsuccessful and who later died from septicaemia, the results of operation were excellent; the local symptoms were relieved and there was major improvement in the neurological picture in those with cord damage.

With three exceptions, Cases 27, 47, and 48, the patients were under the care of Prof. J. H. Kellgren in the University Department of Rheumatism Research or of Mr. D. Lloyd Griffiths or Mr. John Charnley in the University Department of Orthopaedic Surgery in the Manchester Royal Infirmary. We are grateful to Dr. E. R. Bickerstaff of the Midland Centre for Neurosurgery, Smethwick, and to Mr. Robert Roaf of the Robert Jones and Agnes Hunt Orthopaedic Hospital, Oswestry, for permission to include Case 27, and to the late Dr. H. Stuart Barber of the Devonshire Royal Hospital, Buxton, and Dr. F. R. Ferguson and Mr. R. T. Johnson of the University Departments of Neurology and Neurosurgery, Manchester Royal Infirmary, for permission to include Cases 47 and 48. Two patients had been treated by cervical fusion for the dislocation before being seen by us, Case 19 by Mr. A. S. Kerr, and Case 22 by Mr. Sayle Creer, to whom we are indebted for information and for the loan of case records. Dr. R. Sykes supplied information about Case 12 who was initially under his care.

Dr. J. S. Lawrence, Director of the Empire Rheumatism Council Field Unit, gave us access to radiographs taken in connexion with surveys of the general population and also provided information regarding the prevalence of rheumatoid arthritis and ankylosing spondylitis in the samples studied. We are also indebted to Dr. J. Ball, who carried out the sheep cell agglutination tests both in the hospital patients and in the population studies.

\section{REFERENCES}

Ball, J. (1950). Lancet, 2, 520.

(1958). Ann. rheum. Dis., 17, 121.

(1960). Personal communication.
Bell, C. (1830, 1844). "The Nervous System of the Human Body", 1st ed., 1830 (Longmans, London); 3rd ed., with additions, 1844, p. 403 . Renshaw, London.

Brocher, J. E. W. (1955). "Die Occipito-Cervical- on Gegend". Thieme, Stuttgart.

Coste, F., Auquier, L., and Civatte, J. (1952). Rev. ज? Rhum., 19, 55.

Coutts, M. B. (1934). Arch. Surg., 29, 297.

Davis, F. W., and Markley, H. E. (1951). Ann. intern. Med., 35, 451.

Grisel, P. (1930). Presse méd., 38, 50.

Jackson, H. (1950). Brit. J. Radiol., 23, 672.

Kornblum, D., Clayton, M. L., and Nash, H. H. (1952). J. Amer. med. Ass., 149, 431.

Kellgren, J. H., and Lawrence, J. S. (1956). Ann. rheum. Dis., 15, 1. (1958). Ibid., 17, 388.

Lawrence, J. S. (1960). Personal communication.

Le Baudour, J., and Freyberg, R. H. (1958). Sem. Hôp. 워 Paris, 34, 1120.

Morrison, R. J. G. (1955). Proc. roy. Soc. Med.,

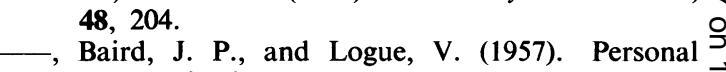
communication.

Perry, J., and Nickel, V. L. (1959). J. Bone Jt Surg., 41A, 37.

Potter, T. A., Barkin, R., and Stillman, J. S. (1954). Ann. rheum. Dis., 13, 364.

Pratt, T. L. C. (1959). J. Fac. Radiol., 10, 40.

Rand, C. W. (1944). "The Neurosurgical Patient: H(TS Problems of Diagnosis and Care", p. 47. Thom Springfield, Ill.

Rolleston, G. L. (1947). Brit. J. Radiol., 20, 288.

Ropes, M. W., Bennett, G. A., Cobb, S., Jacox, R., and Jessar, R. A. (1959). Ann. rheum. Dis., 18, 49.

Sèze, S. de, Djian, A., and Caroit, M. (1957). Rev. Rhum., 24, 192.

Sharp, J. (1957). Brit. med. J., 1, 975. and Purser, D. W. (1957). Ann. rheum. Dis., 16, 147 .

(1961). In preparation.

, - , and Lawrence, J. S. (1958). Ann. rheum. Dis., 17, 303.

Stammers, F. A. R. (1956). Personal communication. and Frazer, P. (1933). Lancet, 2, 1203.

Storey, G. (1958). Ann. phys. Med., 4, 216.

Thomas, A. E. (1955). Ann. rheum. Dis., 14, 259.

Vignon, G., and Patet, R. (1955). Rev. lyon. Méd., 4, 693.

Watson-Jones, R. (1932). Proc. roy. Soc. Med., 25, 586. Werne, S. (1957). Acta orthop. scand., Suppl. 23. Oั Wilkinson, M., and Bywaters, E. G. L. (1958). Ann. N rheum. Dis., 17, 209.

\section{APPENDIX}

\section{Atypical Spondylitis}

Case 19.-In 1945, at the age of 18 , this man who had $\stackrel{\text { ? }}{+}$ previously enjoyed excellent health developed painful 0 stiffness of the neck mainly at night. After a month 
his head "fell forward" and he developed intense pain radiating from the occipital to the temporal regions and back of the eyes, particularly on jarring movements such as those experienced when riding in buses. Atlantoaxial dislocation was diagnosed and he was treated by 10 weeks' halter traction followed by immobilization in plaster and leather collars for 7 months. At the end of this period he was symptom-free and had a full range of neck movement and he resumed his normal activities including sport. After 18 months, however, his symptoms recurred and in $1949 \mathrm{Mr}$. A. S. Kerr performed occipito-cervical fusion with complete relief. He was again symptom-free for 2 years but then developed mild stiffness and swelling of the left knee and some months later aching of the lumbar region; the latter was completely relieved by a spinal support. During the 6 months before he first attended the Rheumatism Centre in 1954 he had developed mild psoriasis and pain arising from the hip joints.

His spine was then painless but rigid apart from a trace of lower cervical movement. He had moderate flexion deformity and slight tilting of the head. His chest expansion was $6 \mathrm{~cm}$. There was synovial thickening and effusion in both knees and mild painful restriction of hip movement. The sedimentation rate was $70 \mathrm{~mm}$. in one hour (Westergren) and the sheep cell agglutination test was negative. Radiographs revealed changes in the sacro-iliac joints, pubic symphysis, and spine compatible with but not entirely typical of ankylosing spondylitis.

This condition was considered to be "atypical spondylitis" (Sharp, 1957), mainly on account of the mode of onset of the illness and the retention of normal cervical mobility after lengthy immobilization in the early stages; the complete relief of lumbar pain from use of a spinal brace, and the presence of psoriasis were also regarded as features unusual in ankylosing spondylitis.

He was given $x$-ray therapy to the hips with complete relief of pain and subsequently to the knees with some benefit. In 1957 a severe iron deficiency anaemia responded rapidly to parenteral iron. When he was last seen in 1958 there was still active but virtually painless arthritis in the knees; there had been slight loss of hip motion since 1954, but the spine was unchanged. There has been no recurrence of cervical symptoms and there were no neurological abnormalities.

Case 21.-When he was 18 years old and serving as a regular soldier in Palestine in 1938, this man developed generalized pain and stiffness in the trunk and limbs with swelling of the fingers. The onset was acute and he was febrile for the first few days. He was confined to bed for 2 months and remained in hospital for 3 months, making a full recovery. Some months later, in 1939, he had an attack of urethritis which cleared in 8 days with sulphonamides. In 1941 he developed painful swelling of the left foot and pain in the right shoulder region. He was admitted to hospital many times and was eventually discharged from the Army on medical grounds in 1945 . The symptoms gradually abated and from 1948 to 1953 he was symptom-free and leading a normal life. One year before his first attendance in September, 1954, he began to have attacks of pain in the low back and one or other buttock and groin; after 9 months these pains became continuous and he also had discomfort in both feet and in the shoulder regions. He had been breathless on effort and had had an intermittent productive cough for 2 years. He had not suffered from dysentery, eye trouble, or skin rashes.

On examination he was plethoric and obese, and had signs of bronchitis. The blood pressure was 175/115 $\mathrm{mm}$. Hg. The left ankle jerk was sluggish. The lumbar spine was somewhat flattened, the dorsal and lumbar regions were rigid, and the cervical region was greatly restricted in motion. The chest expansion was $1 \mathrm{~cm}$. The ankle, tarsal, and metatarso-phalangeal joints were diffusely thickened; the latter were dorsally subluxated and the right tarsus was painful and limited in motion. Both acromio-clavicular joints were tender with slight restriction of shoulder girdle movement. and there were focal tender areas on the iliac crests, left ischial tuberosity, and left acromion process.

The sedimentation rate was $73 \mathrm{~mm}$. in the first hour (Westergren) and the sheep cell agglutination test was negative. Radiographically the sacro-iliac joints were fused and there was extensive ossification of spinal ligaments and disk margins, and periosteal new bone formation on the margins of the pelvis and plantar surface of the left os calcis. Squaring of the vertebral bodies (Rolleston, 1947) was absent.

This was classed as a case of "atypical" spondylitis, since it was felt that the patient was possibly suffering from Reiter's disease in an incomplete form.

After $x$-ray therapy to the spine and later to the left shoulder and right sterno-clavicular joints he was much improved. At a routine follow-up visit 2 years later, in 1957, the improvement had been maintained, though he was complaining of some pain in the upper cervical and sub-occipital regions principally in the mornings, but there was no radiographical evidence of atlantoaxial subluxation.

He requested an appointment in September, 1958, some months before his routine visit was due, as in the previous 6 weeks he had developed severe pain, typical of that of a mobile atlanto-axial displacement, and his head had become fixed in a flexed position and tilted downwards to the left. For the same period he had had intermittent paraesthesiae over the dorsum of the right foot although no definite sensory or other neurological abnormalities could be demonstrated apart from sluggish ankle jerks. Radiographs revealed forward subluxation of the atlas of moderate degree (Table VII).

The displacement was reduced by skull traction and from the time this was instituted he had no recurrence of paraesthesiae in the foot. When he was last seen, 9 months after occipito-cervical fusion, his spine was rigid and painless apart from very mild lower cervical pain and there were no neurological abnormalities.

Case 22.-A housewife who was aged 41 when she attended in 1954 had suffered repeated attacks of arthritis of the limbs and spine following intermittent throat 
infections since the age of 11 . She had severe mitral and aortic valvular lesions, complete rigidity of the spine, and hypermobility of most of her limb joints, but there was limitation of movement in the joints of the shoulder girdles and of the left index and medius. Cutaneous sensation was impaired in these fingers, which were wasted. It was suspected that spinal and cardiac changes might have resulted from recurrent rheumatic fever (Thomas, 1955; Sharp, 1957).

During an attack at age 29 her neck had become very restricted in movement and 4 years later she had gradually developed a severe atlanto-axial dislocation associated with pyramidal signs. This had failed to respond to prolonged immobilization and when she was aged 36 Mr. Sayle Creer and Mr. A. N. Guthkelch removed the posterior arch of the atlas and performed occipitocervical fusion.

When she attended the Rheumatism Centre 5 years later after a further attack of polyarthritis, she had mild residual pyramidal signs and sensory changes in the left upper and lower limbs. She died from congestive heart failure at age 43 .

\section{Luxation spontanée atlanto-axiale dans la spondylarthrite ankylosante et l'arthrite rhumatismale}

\section{RÉSUMÉ}

De l'étude des radiographies de la colonne cervicale des membres de la population générale on conclut que, à partir de 45 ans, un écart de plus de $3 \mathrm{~mm}$. entre l'apophyse odontoïde de l'axis et l'arc antérieur de l'atlas, noté sur des projections latérales habituelles, est généralement anormal et très probablement associé à l'arthrite rhumatismale, bien que chez les individus jeunes un écart de $4 \mathrm{~mm}$. puisse être normal. Des études cliniques font croire que, quelquefois, même un écart de $3 \mathrm{~mm}$. peut être pathologique.

La fréquence d'un déplacement atlanto-axial, défini ci-dessus, chez des membres de la population générale présentant un signe quelconque d'arthrite rhumatismale était de 32 pour mille; chez ceux avec un tableau clinique d'arthrite rhumatismale cette fréquence était de 64 pour mille et chez des arthritiques rhumatisants hospitalisés elle s'élevait à 189 pour mille. Cette lésion se voyait moins souvent dans la spondylarthrite ankylosante, mais ce travail ne suffit pas pour en définir la fréquence exacte.

On a étudié les traits cliniques et radiologiques chez 22 malades atteints de spondylarthrite ankylosante et chez 26 malades atteints d'arthrite rhumatismale, ayant développé un déplacement spontané de l'atlas sur l'axis. On a trouvé que chez ceux atteints de spondylarthrite il y avait toujours des symptômes de déplacement, tandis que dans une proportion importante des cas d'arthrite rhumatismale de tels symptômes étaient absents et l'on arrivait alors au diagnostic à l'aide des radiographies prises avec la tête en flexion et en extension; quelquefois un déplacement mobile n'était pas apparent sur une seule radiographie latérale prise en position neutre.

Les traits cliniques caractéristiques du déplacement étaient:

(1) Douleur dans la partie supérieure du cou, s'irradiant vers la région occipitale et quelquefois vers la région temporale et frontale, très aggravée par des secousses.

(2) Difficulté à relever la tête après avoir regardé en bas, souvent accompagnée d'une difficulté à se raser sous le menton et de la sensation queD la tête "tendait à tomber en avant".

(3) Aplatissement de la courbe occipito-cervicale accompagné souvent d'un torticolis plus ou moins intense.

Dans quelques cas le déplacement se manifestait par: des signes médullaires; dans certains de ces cas le diagers nostic avait été très difficile et chez le premier maladę on ne l'a fait qu'à l'autopsie. En tout, 6 malades rhuma-C tisants et 7 malades spondylarthritiques ont présenté des lésions médullaires. La gravité des altérations neuro $\frac{\mathcal{D}}{\partial}$ logiques se rapportait au degré du rétrécissement de laథ moelle, malgré la magnitude du déplacement.

Un déplacement peut se stabiliser tout seul, sanş traitement, mais on ne sait pas si c'est souvent le cas $\vec{\nabla}$ et dans les deux maladies on a observé une aggravation constante du déplacement non traité. Pour cette raisonon a traité la plupart des cas par des colliers, qui per- $\omega$ mettaient en général une diminution de la douleur e⿻ి quelquefois du degré du déplacement et de la mobilitêَ anormale. Chez un malade atteint d'arthrite rhuma ĩ tismale, des altérations neurologiques graves ont rétro? gressé aprês l'application de la traction sur la crâne $\overrightarrow{-}$ il $y$ a eu une détérioration lorsqu'on a appliqué un plâtre Minerva suivi d'un collier massif de cuir. On ab observé une augmentation du déplacement quand le malade etait dans le plâtre.

Quatre malades rhumatisants furent traités par $1 a Z$ fusion occipito-cervicale, l'indication de l'opération ayant été dans tous les cas la présence de signes neuro $\frac{\rho}{5}$ logiques. L'indication principale fut la même dansquatre cas sur onze opérés de spondylarthrite; chez cinfo autres on procéda à l'opération à cause de la douleß̂? chez un autre à cause d'une grave déformation et cy le onzième parce que le déplacement augmentait malgr:o le collier. A l'exception d'un malade atteint d'arth rhumatismale, chez qui la fusion avait échoué et qub mourut plus tard de septicémie, les résultats de l'opéra ڤొ tion furent excellents; les symptômes locaux furen soulagés et le tableau neurologique fut nettemen amélioré chez ceux qui avaient une lésion de la moelle.

\section{Luxación espontánea atlanto-axoidea en la espondilitis anquilosante $y$ artritis reumatoide \\ Sumario}

Del estudio de radiografías de la columna cervica entre miembros de la población general se concluye que en edades superiores a 45 años, una separación de más. de $3 \mathrm{~mm}$. entre la apófisis odontoide del axis y el arcó anterior del atlas, observada en proyecciones laterales corrientemente empleados, es usualmente anormal muy probablemente asociada con artritis reumatoide $\frac{\text { O }}{2}$ aunque en individuos más jóvenes una separación des $4 \mathrm{~mm}$. puede ser normal. Los estudios clínicos sugierero que a veces una separación de solamente $3 \mathrm{~mm}$. puede ser patológica.

La presencia de desplazamiento atlanto-axoideo, comø expresado anteriormente, entre los miembros de lif población general con algún síntoma indicativo dê artritis reumatoide era 32 por mil, en aquellos con signos clínicos de la enfermedad 64 por mil, y entre los enfermos hospitalizados con artritis reumatoide la proporción fué 189 por mil. La lesión apareció con menos frecuenciof en la espondilitis anquilosante, pero no es posible estabes lecer en este estudio la proporción exacta.

Se estudiaron los rasgos clínicos y radiográficos en 22 enfermos con espondilitis anquilosante y 26 con? 
artritis reumatoide que habían desarrollado un desplazamiento espontáneo del atlas sobre el axis; en los enfermos espondílicos se vieron invariablemente signos clínicos de desplazamiento, ausentes, sin embargo, en un número considerable de enfermos con artritis reumatoide; en tales casos se llegó al diagnóstico solamente por radiografías regulares tomadas en flexión y extensión de la columna cervical; un desplazamiento movil no se pudo ver a veces en una radiografía lateral tomada con el cuello en posición neutra.

Los rasgos clínicos característicos del desplazamiento fueron:

(1) Dolor en la parte superior del cuello radiando a la región occipital y a veces a las regiones temporal y frontal, grandemente agravado por movimientos bruscos.

(2) Dificultad para dirigir la cabeza hacia atrás después de haber estado mirando al suelo, frecuentemente acompañada de dificultad para afeitarse debajo de la barbilla y sensación de que la cabeza tiende a "caerse hacia adelante".

(3) Aplanamiento de la curva occipito-cervical, acompañado frecuentemente por tortícolis en cierto grado.

En unos cuantos casos las primeras manifestaciones del desplazamiento fueron signos de lesión medular; en algunos de estos casos el diagnóstico fué muy difícil y en el primer enfermo que presentó este tipo de comienzo solamente se llegó al diagnóstico en la autopsia. En total, 6 de los enfermos reumáticos y 7 de los espondílicos presentaron evidencia de lesión medular. La gravedad de las alteraciones neurológicas estuve más bien en relación con el grado de aplastamiento de la médula que con el grado de desplazamiento.

Estabilización espontánea del desplazamiento puede ocurrir sin ser tratado, pero se desconoce la frecuencia con que esto ocurre y, por otra parte, en ambas enfermedades en algunos enfermos el desplazamiento no tratado tendía a empeorar. La mayoría de los casos fué por lo tanto tratada con soportes del cuello, usualmente con satisfactoria disminución del dolor $y$ algunas veces con reducción del grado de desplazamiento y de la anormal movilidad. En un enfermo con artritis reumatoide, alteraciones neurológicas graves regresaron tras tracción continua del cuello, apareciendo un empeoramiento neurológico progresivo tras la aplicación de un Minerva de yeso seguido de un soporte de cuero continuo para el cuello. Aumento del grado de desplazamiento durante el período de tratamiento con yeso ha sido observado.

Cuatro de los enfermos con artritis reumatoide fueron tratados por fusión occipito-cervical, considerándose como indicación para el tratamiento operativo la presencia de signos neurológicos. Esta misma fué la principal indicación en cuatro de los once enfermos espondílico tratados operatoriamente, siendo la principal indicación en los otros: dolor en cinco, grave deformidad en uno y aumento del desplazamiento a pesar del soporte del cuello en uno. Con la excepción de uno de los enfermos con artritis reumatoide, en quien la fusión fracasó quien falleció más tarde de septicemia, los resultados de la operación fueron excelentes; los síntomas locales mejoraron y en los enfermos con lesión medular el cuadro neurológico mejoró más notoriamente. 